\title{
Multiscale Investigations of Nanoprecipitate Nucleation, Growth, and Coarsening in Annealed low-Cr Oxide Dispersion Strengthened FeCrAl Powder
}

\author{
Caleb P. Massey ${ }^{\mathrm{a}, 1}$, Sebastien L. Dryepondt ${ }^{\mathrm{b}}$, Philip D. Edmondson ${ }^{\mathrm{c}}$, Matthew G. Frith ${ }^{\mathrm{c}}$, Kenneth \\ C. Littrell ${ }^{\mathrm{b}}$, Anoop Kini ${ }^{\mathrm{d}}$, Baptiste Gault ${ }^{\mathrm{d}}$, Kurt A. Terrani ${ }^{\mathrm{b}}$, and Steven J. Zinkle ${ }^{\mathrm{a}, \mathrm{b}}$ \\ ${ }^{a}$ Department of Nuclear Engineering, University of Tennessee, Knoxville, TN 37996 \\ ${ }^{b}$ Oak Ridge National Laboratory, Oak Ridge, TN 37831 \\ ${ }^{c}$ Argonne National Laboratory, Argonne, IL 60439 \\ ${ }^{\mathrm{d}}$ Max-Planck-Institut für Eisenforschung GmbH, Düsseldorf, Germany \\ Corresponding author: cmassey7@utk.edu
}

Keywords: atom probe tomography, small angle neutron scattering, oxide dispersion strengthened (ODS) alloy, precipitation

\begin{abstract}
A major challenge in the design of oxide dispersion strengthened (ODS) FeCrAl alloys is the optimization of the fine-scale particle size distribution that provides both beneficial mechanical properties and irradiation resistance. To address this obstacle, the nucleation, growth, and coarsening of the fine-scale (Y,Al,O) nanoprecipitates within an ODS FeCrAl was studied using atom probe tomography (APT) and small-angle neutron scattering (SANS). Mechanically alloyed $\mathrm{Fe}-10 \mathrm{Cr}-6.1 \mathrm{Al}-0.3 \mathrm{Zr}+\mathrm{Y}_{2} \mathrm{O}_{3} \mathrm{wt}$ \% $\%$ (CrAZY) powders were heated in-situ from $20-1000^{\circ} \mathrm{C}$ to capture the nucleation and growth the nanoprecipitates using SANS. Furthermore, CrAZY powders were annealed at $1000^{\circ} \mathrm{C}, 1050^{\circ} \mathrm{C}$, and $1100^{\circ} \mathrm{C}$ at ageing times from $15 \mathrm{~min}$ to $500 \mathrm{~h}$ followed by either APT or magnetic SANS to study the structure, composition, and coarsening kinetics of the nanoprecipitates. In-situ SANS results indicate nanoprecipitate nucleation and growth at low temperatures $\left(200-600^{\circ} \mathrm{C}\right)$. APT results indicate compositions corresponding to the YAG stoichiometry with a possible transition towards the YAP phase for larger precipitates after sufficient thermal ageing. However, magnetic SANS results suggest a defective structure for the nanoprecipitates indicated by deviations of the calculated A-ratio from stochiometric (Y,Al,O) phases. Particle coarsening kinetics follow $\mathrm{n}=6$ power law kinetics, but the mechanism cannot be explained through the dislocation pipe diffusion mechanism. The potential effect of precipitate coarsening during pre- and post-consolidation heat treatments on the irradiation resistance of ODS FeCrAl alloys is discussed with respect to sink strength maximization.
\end{abstract}




\section{GRAPHICAL ABSTRACT}

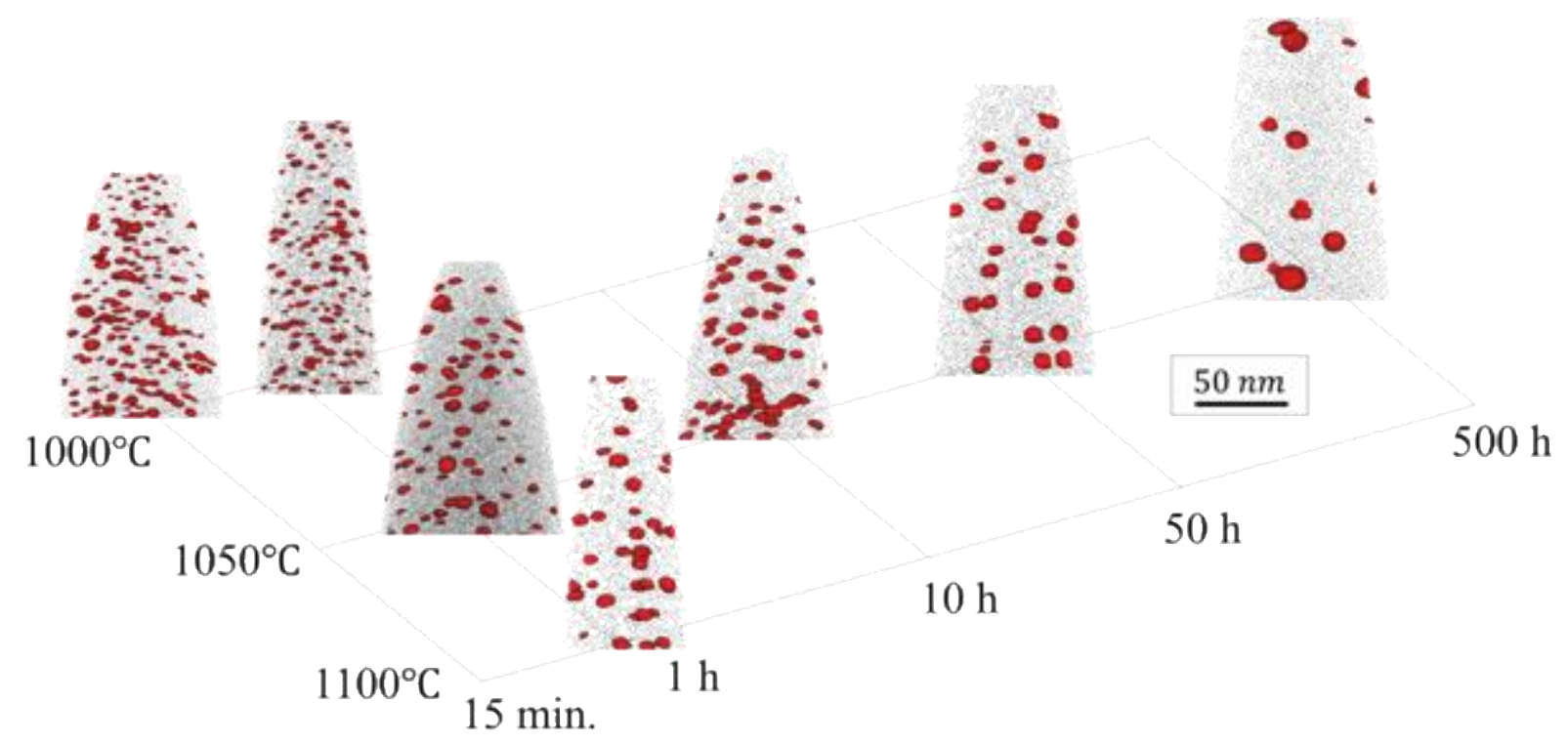

This manuscript has been authored by UT-Battelle, LLC, under Contract No. DE-AC05-000R22725 with the U.S. Department of Energy. The United States Government retains and the publisher, by accepting the article for publication, acknowledges that the United States Government retains a non-exclusive, paid-up, irrevocable, worldwide license to publish or reproduce the published form of this manuscript, or allow others to do so, for United States Government purposes. The Department of Energy will provide public access to these results of federally sponsored research in accordance with the DOE Public Access Plan (http://energy.gov/downloads/doe-public-access-plan). 


\section{Introduction}

Advanced fusion and fission nuclear reactor design concepts will require materials that are suited for high operating temperatures and irradiation doses [1]. Even for existing light water reactors (LWR's), new materials are being investigated as drop-in replacements for existing Zrbased nuclear fuel cladding that exhibit better high temperature strength and oxidation resistance in the event of design basis or beyond design basis accident scenarios [2]. The consequences of not having an oxidation resistant accident tolerant fuel (ATF) cladding has already been realized in 2011 with respect to the Fukushima Daiichi nuclear accident that has subsequently accelerated the development of these ATF cladding alternatives. Oxide dispersion strengthened (ODS) $\mathrm{FeCrAl}$ alloys are one class of materials that attempt to address these challenges in both advanced reactor concepts and in current LWR's due to their high temperature strength, irradiation resistance, and oxidation resistance in the presence of high temperature steam [3, 4].

The oxidation resistance of wrought $\mathrm{FeCrAl}$ alloys has been well recognized in the literature, with $\mathrm{FeCrAl}$ exhibiting 100x slower oxidation kinetics in comparison to conventional Zr-based claddings $[2,5]$. In addition, the ODS FeCrAl concept has already been previously established for components operating at high temperature through the study of legacy alloys PM2000 and MA956 [6]. These legacy ODS FeCrAl alloys have a high number density of $(\mathrm{Y}, \mathrm{Al}, \mathrm{O})$ rich precipitates within the microstructure that help refine the grain size and inhibit dislocation motion, resulting in the improvement of alloy strength to higher temperatures characteristic of those seen in advanced reactors or nuclear accident scenarios. The combination of the fine grain structure and a high number density of nanoscale precipitates also results in abnormally high recrystallization temperatures on the order of 0.9TM [7-9], which aids in the stability of the microstructure at extended operating times at higher temperatures.

One major drawback for legacy high-Cr ODS FeCrAl (>14 wt\% Cr) alloys such as MA956 and PM2000 in LWR operating temperature regimes is the tendency for the precipitation of a deleterious $\alpha^{\prime}$-Cr phase through a $\alpha^{\prime}$ - $\alpha$ phase separation process between $300^{\circ} \mathrm{C}-450^{\circ} \mathrm{C}[10$ 14] that is accelerated in irradiation environments [15-17]. The presence of $\alpha^{\prime}$-Cr precipitates in high-Cr ferritic alloys has been linked to a reduction in alloy ductility and a deterioration in fracture toughness $[18,19]$. In an attempt to mitigate the formation of this phase in ODS FeCrAl alloys, new ODS FeCrAl alloys with lower $\mathrm{Cr}$ content (10-12 wt\%) have recently been under development for nuclear applications. These low-Cr ODS FeCrAl alloys exhibit the same high temperature strength as legacy ODS FeCrAl alloys and are resistant to oxidation in steam environments to temperatures as high as $1400^{\circ} \mathrm{C}[3,4]$.

Although primary differences between wrought FeCrAl alloys and the ODS FeCrAl variants are directly attributed to the characteristics of the nanoscale dispersions of precipitates within the microstructure, fundamental studies concerning the understanding and optimization of the distributions of these nanoscale features are surprisingly scarce in the literature. In fact, most studies that currently exist for ODS FeCr and ODS FeCrAl alloys focus only on the characteristics of these oxide precipitates after thermomechanical processes such as extrusion with little attention paid to the preliminary annealing step when these precipitates nucleate, grow, and coarsen within the microstructure. The use of subsequent high temperature recrystallization treatments $\left(1330^{\circ} \mathrm{C}, 1 \mathrm{~h}\right)$ for alloys like MA956 [20, 21], coupled with some aspects of the processing procedures being proprietary for industry alloys PM2000 and MA956, further complicates the comparison of as-consolidated ODS FeCrAl alloys in literature. With these challenges in mind, a variety of (Y,Al,O) phases have been identified for the fine-scale precipitates within the ODS FeCrAl microstructure. These compositions and structures include 
yttrium aluminum tetragonal (YAT, $\mathrm{Y}_{3} \mathrm{Al}_{5} \mathrm{O}_{12}$ ) [20], cubic yttrium aluminum garnet (YAG, $\mathrm{Y}_{3} \mathrm{Al}_{5} \mathrm{O}_{12}$ ) [22], yttrium aluminum perovskite (YAP, $\mathrm{YAlO}_{3}$ ) [21, 23, 24], yttrium aluminum hexagonal $\left(\mathrm{YAH}, \mathrm{YAlO}_{3}\right.$ ) [23], and yttrium aluminum monoclinic ( $\mathrm{YAM}, \mathrm{Y}_{4} \mathrm{Al}_{2} \mathrm{O}_{9}$ ) $[25,26]$.

The importance of understanding the underlying kinetics of nanoprecipitate formation during ODS alloy consolidation has recently been shown by Hoelzer and colleagues for an ODS FeCr alloy 14YWT, where the authors found that higher ductility and fracture toughness can be achieved for ODS alloys by utilizing a pre-extrusion annealing step at lower temperature $\left(850^{\circ} \mathrm{C}\right)$ for nanoprecipitate formation followed by extrusion at higher temperature for grain size optimization. In that study, the nanoprecipitate sizes $(\sim 3 \mathrm{~nm}$ dia. $)$ and number densities $\left(\sim 10^{23} \mathrm{~m}^{-}\right.$ $\left.{ }^{3}\right)$ were shown to be rather resistant to extrusion temperature for alloys extruded at either $850^{\circ} \mathrm{C}$, $1000^{\circ} \mathrm{C}$, and $1150^{\circ} \mathrm{C}$ after the pre-extrusion anneal [27]. This result contrasts with previous results on ODS FeCr alloys extruded at various temperatures that indicated a decrease in number density and an increase in nanoprecipitate size as extrusion temperature increases. Fundamental studies on the nucleation and growth of nanoscale precipitates in thermally annealed PM2000 powders after $1 \mathrm{~h}$ anneals at temperatures ranging from $850^{\circ} \mathrm{C}-1150^{\circ} \mathrm{C}$ have come the closest at resolving the time and temperature dependence of $(\mathrm{Y}, \mathrm{Al}, \mathrm{O})$ nanoprecipitate populations in ODS $\mathrm{FeCrAl}$ alloys, and also show the same increase in precipitate size and decrease in number density as a function of annealing temperature. However, even these powder annealing studies have not yet captured the initial nucleation and growth kinetics for the smallest precipitates at shorter time scales $(<1 \mathrm{~h})$.

The results presented in this study aim to bridge the gap in knowledge pertaining to the initial development of (Y,Al,O) nanoprecipitates in ODS FeCrAl powder during the preconsolidation annealing stage of alloy processing. Through a multiscale approach, both small angle neutron scattering (SANS) and atom probe tomography (APT) are utilized to establish the nucleation, growth, and coarsening regimes in powders annealed at various times and temperatures. In-situ thermal annealing experiments using SANS are interpreted in conjunction with a combined APT+SANS investigation of ex-situ annealed ODS FeCrAl powders to assess changes in nanoprecipiate dispersions at time scales ranging from $15 \mathrm{~min}$ to $500 \mathrm{~h}$, thereby constructing a more robust understanding of how the initial powder annealing stage affects the resultant nanoprecipitate distributions in as-consolidated ODS FeCrAl alloys.

\section{Materials and Methods}

\subsection{Specimen Preparation}

The ODS FeCrAl powder studied in this work was produced using the mechanical alloying approach. Gas atomized Fe-10Cr-6.1Al-0.3Zr (wt.\%) powder supplied by ATI Powder Metals (44-149 $\mu \mathrm{m}$ particle size) and nanocrystalline $\mathrm{Y}_{2} \mathrm{O}_{3}$ (17-31 nm crystallite size) were ball milled for 40h in a high energy Zoz Simoloyer ball mill under Ar atmosphere using steel milling media. The resulting $\mathrm{CrAZY}(\mathrm{Fe}-\underline{\mathrm{Cr}}-\underline{\mathrm{Al}}-\underline{\mathrm{Zr}}-\underline{\mathrm{Y}})$ powder has previously been extruded into cylindrical rods using hot extrusion at either $1050^{\circ} \mathrm{C}(4 \mathrm{H} 15 \mathrm{C})$ or $1100^{\circ} \mathrm{C}(\mathrm{CrAZY}-\mathrm{H} 1)$ after thermally annealing the powder for $1 \mathrm{~h}$ at the desired extrusion temperature. Details concerning the microstructure and mechanical properties of the as-extruded CrAZY rods can be found in previous communications [28, 29]. Inductively coupled plasma optical emission spectroscopy (ICP-OES) was performed by the company DIRATS on the as-milled CrAZY powder used in this study in addition to the as-extruded rods. The resulting bulk compositions are reported in Table 1. 
Table 1

Chemical Analysis Results for the CrAZY powder and alloys studied in this work (in at. \%)

\begin{tabular}{lllllllll}
\hline Specimen & $\mathrm{Fe}$ & $\mathrm{Cr}$ & $\mathrm{Al}$ & $\mathrm{Zr}$ & $\mathrm{Y}$ & $\mathrm{O}$ & $\mathrm{C}$ & $\mathrm{N}$ \\
\hline ZY (as-milled powder) & 77.42 & 9.73 & 11.78 & 0.15 & 0.13 & 0.43 & 0.25 & 0.04 \\
4H15C (ZY15C60*) & 77.80 & 9.58 & 11.33 & 0.15 & 0.12 & 0.61 & 0.01 & 0.25 \\
CrAZY-H1 (ZY11C60*) & 77.66 & 9.76 & 11.40 & 0.15 & 0.13 & 0.37 & 0.30 & 0.06 \\
\hline
\end{tabular}

* Modified sample designation in this work to match naming convention

Since the rods extruded at $1050^{\circ} \mathrm{C}$ and $1100^{\circ} \mathrm{C}$ were subjected to controlled thermal annealing treatments for $1 \mathrm{~h}$ prior to extrusion, the nanoprecipitate distributions within these two alloys provide two distinct data points for the understanding of coarsening kinetics for the finescale (Y-Al-O) CrAZY nanoprecipitates and will be compared to the annealed CrAZY powders in this study. To more easily reference and compare these consolidated alloys, the names of the CrAZY rods have been altered to ZY15C60 and ZY11C60 to match the annealed CrAZY powder naming convention (Table 1). For the naming convention, "ZY" refers to the addition of $\mathrm{Zr}$ and $\mathrm{Y}$ for the ODS FeCrAl powder, while the $(10,15,11) \mathrm{C}$ refer to the annealing temperatures $(1000,1050 \text {, or } 1100)^{\circ} \mathrm{C}$. The final part of the name is the duration in minutes (or hours "h" if specified) for the annealed CrAZY powder.

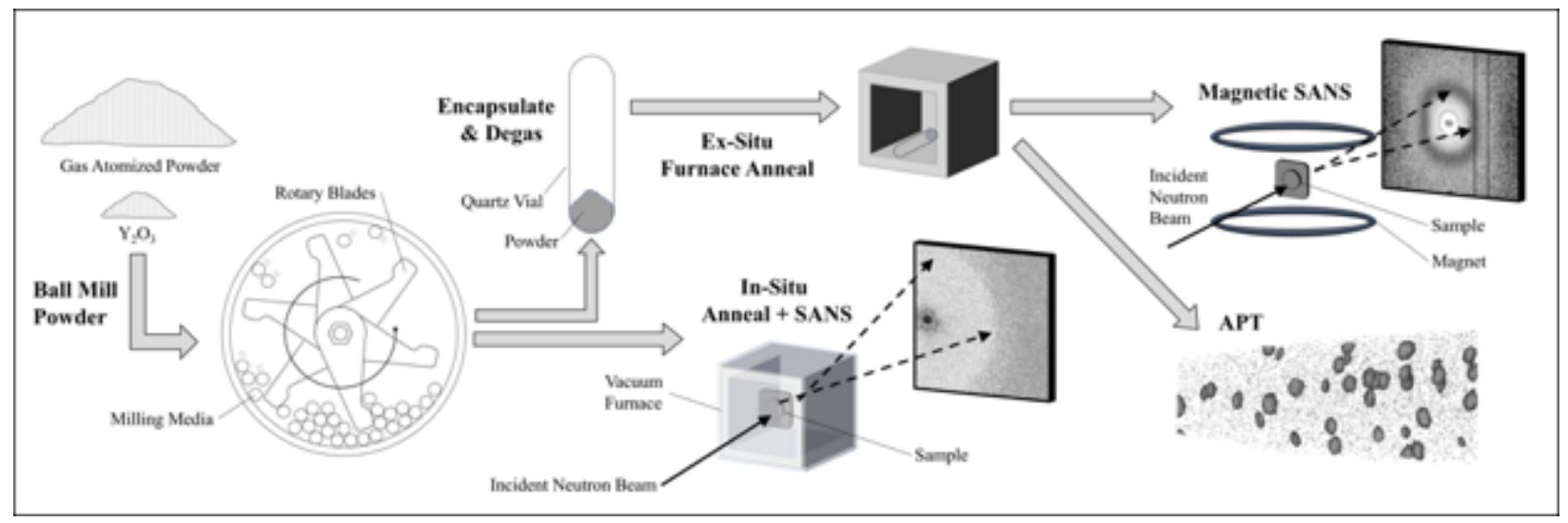

Fig. 1. Process diagram for annealed powder specimen preparation and evaluation

The general process for the production and analysis of the CrAZY powder is illustrated in Fig. 1. After the powder has been mechanically alloyed, it was either encapsulated in quartz vials evacuated to $<10^{-4}$ Torr, or the powder was packed into molybdenum foil packets for in-situ SANS experiments. The CrAZY powders encapsulated in evacuated quartz vials were subjected to ex-situ thermal annealing treatments in either a box furnace or a tube furnace at either $1000^{\circ} \mathrm{C}$ or $1050^{\circ} \mathrm{C}$ for various times. The experimental matrix for ex-situ heat treatments is provided in Table 2. After the ex-situ furnace anneals, powders were extracted from the quartz vials, mounted in conductive epoxy, and metallographically polished to a colloidal silica finish $(0.05$ $\mu \mathrm{m})$. In addition, some of the extracted powder was packed into aluminum foil packets for room temperature SANS measurements for direct comparison with APT results. 
Table 2

Ex-Situ Specimens

\begin{tabular}{ccccc}
\hline Sample & $\begin{array}{c}\text { Target Furnace Temp } \\
{\left[{ }^{\circ} \mathrm{C}\right]}\end{array}$ & Time $[\mathrm{h}]$ & SANS & APT \\
\hline ZY10C15 & 1000 & 0.25 & $\checkmark$ & $\checkmark$ \\
ZY10C30 & 1000 & 0.5 & $\checkmark$ & \\
ZY10C60 & 1000 & 1 & $\checkmark$ & $\checkmark$ \\
ZY10C120 & 1000 & 2 & $\checkmark$ & \\
ZY15C60* & 1050 & 1 & & $\checkmark$ \\
ZY15C10h & 1050 & 10 & & $\checkmark$ \\
ZY15C50h & 1050 & 50 & & $\checkmark$ \\
ZY15C500h & 1050 & 500 & & $\checkmark$ \\
ZY11C60* & 1100 & 1 & & $\checkmark$ \\
\hline
\end{tabular}

One major difficulty in the interpretation of results for samples annealed in furnaces exsitu is the lack of careful control of the powder heating profile. Although it is commonplace for authors to simply specify the length of the pre-extrusion anneal (i.e. $1 \mathrm{~h}$ at $850^{\circ} \mathrm{C}$ for the SM170 heat of 14YWT [27]), the assumption of an isothermal anneal doesn't take into consideration the time required for the powder to heat up to the effective pre-extrusion temperature. To estimate the heating profile that the powder experiences for short-duration annealing treatments in this study, a mild steel can design previously used for the extrusion of low-Cr ODS FeCrAl alloys [28] was packed with $\sim 400 \mathrm{~g}$ of powder, and a thermocouple was placed in the center of the powder volume. This can was then heated in the same furnace used for extrusions at Oak Ridge National Laboratory (ORNL) for $1 \mathrm{~h}$ at $1000^{\circ} \mathrm{C}$ to record the powder heating profile as a function of time. During the first 30 minutes of the anneal, the powder remains below the target temperature, signifying a significant time-temperature dependence for annealed powders at short annealing durations (Fig. 2). As the masses of the powders subjected to ex-situ annealing treatments in this study (Table 2$)$ are smaller $(\sim 10 \mathrm{~g})$ in comparison to the sample used for the extrusion can heating profile measurement $(\sim 200 \mathrm{~g})$, it is assumed in this study that thermal gradients developed during the transient heating stage are minimal for the large thermal fluxes associated with the high temperatures used $\left(\geq 1000^{\circ} \mathrm{C}\right)$. Thus, for the samples investigated in this work, it is assumed that the temperature profiles for powder samples annealed at $1000^{\circ} \mathrm{C}$ will be identical to the measured temperature profile and that the measured profile can be realistically scaled to higher temperatures $\left(1050^{\circ} \mathrm{C} \& 1100^{\circ} \mathrm{C}\right)$. 


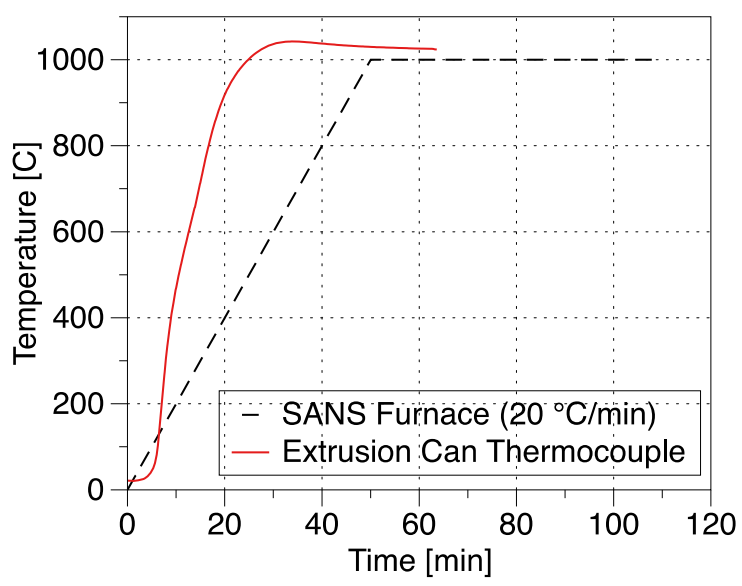

Fig. 2. Measured ex-situ and estimated in-situ heating profiles for annealed CrAZY powders

\subsection{Data Collection - APT}

APT specimens were prepared by means of a widely used focused ion-beam (FIB) liftout technique [30] using a FEI Quanta 3D dual-beam FIB at the Low Activation Materials Development and Analysis (LAMDA) Laboratory at ORNL [31]. Final tip sharpening was performed on the aforementioned FEI Quanta or using a FEI Helios 600 FIB at the Max-PlanckInstitut für Eisenforschung (MPIE) in Düsseldorf, Germany. A final 5kV Ga ion cleaning step was added to minimize $\mathrm{Ga}$ ion implantation from FIB sample preparation. Samples were immediately transferred to a vacuum environment $\left(10^{-8}\right.$ Torr) to minimize sample degradation and oxidation prior to data acquisition. APT characterization on each specimen was performed using either a Cameca model 4000X HR local electrode atom probe (LEAP) at the Center for Nanophase Materials Sciences (CNMS) at ORNL or using a Cameca model 5000 XR LEAP at MPIE. APT data collection for all specimens was performed in laser pulsing mode using a laser energy of $32 \mathrm{pJ}$ and a laser pulse rate of $200 \mathrm{kHz}$. The specimen temperature was held at a temperature of $50 \mathrm{~K}$, and the target detection rate of 5 ions per 1000 laser pulses was set to minimize multiple ion detector hits. At least two specimens per sample condition were analyzed, with at least 10 million collected ions per specimen to ensure statistically significant sample sizes. Data reconstruction and analysis was performed using Cameca's Integrated Visualization \& Analysis Software (IVAS) package (version 3.6.8) [32-35]. For cluster identification and quantification, the maximum separation method was implemented using cluster identification algorithms built into the IVAS software package [32, 34, 35].

From the results of the maximum separation method, the precipitate sizes and number densities were calculated assuming spherical precipitates coherent with the surrounding ferritic matrix. The spherical equivalent radius developed by previous authors has been extended to the $(\mathrm{Y}, \mathrm{Al}, \mathrm{O})$ nanoprecipitates in this work [36-38], where the radius of each precipitate is:

$R_{p}=\left(\frac{\left(N_{p} / Q\right)}{\frac{4}{3} \pi \rho}\right)^{1 / 3}$

where $\mathrm{N}_{\mathrm{p}}$ is the total number of atoms found in each precipitate, $\rho$ is the atomic density of bcc $\alpha$ Fe $\left(84.3\right.$ atoms $\left./ \mathrm{nm}^{3}\right)$, and Q is the detection efficiency for the LEAP used for data acquisition. 
Since the smallest $(Y, A 1, O)$ nanoprecipitates $(\mathrm{d}<5 \mathrm{~nm})$ have been shown to be either semicoherent or coherent with the surrounding ferritic matrix after nucleation and growth [39], and because the lattice parameters between the nanoprecipitates and the matrix deviate by only $\sim 2 \%$ [26], it is assumed that the atomic density is constant and equal to the theoretical atomic density of bcc $\alpha$-Fe. The detection efficiencies (Q) of the 4000X HR and 5000 XR model LEAPs are 0.36 and 0.52 , respectively. The corresponding number density of precipitates is computed by knowing the total number of precipitates found in the control volume $\left(\mathrm{n}_{\mathrm{p}}\right)$ and the total number of atoms in the control volume $\left(\mathrm{N}_{\text {tot }}\right)$ :

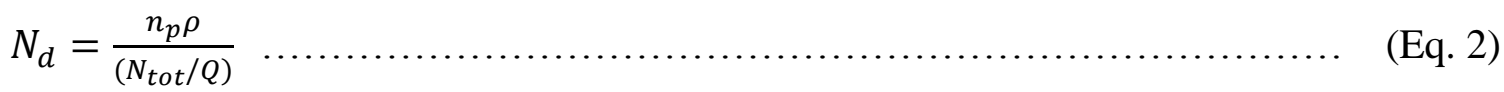

Although a strength of the APT technique is its ability to perform elemental mapping and quantification at the near atomic scale [40], the accuracy of this technique is highly subject to the correct binning of the mass-to-charge ratio spectrum. In the case of the CrAZY powders and alloys studied in this work, there are multiple instances where peak overlaps occur that can provide error in the compositional measurements of both the matrix and the precipitates. For example, mass-to-charge ratios at peaks corresponding to $27 \mathrm{Da}\left({ }^{27} \mathrm{Al}^{+1},{ }^{54} \mathrm{Cr}^{+2},{ }^{54} \mathrm{Fe}^{+2}\right), 54 \mathrm{Da}$ $\left({ }^{54} \mathrm{Cr}^{+1},{ }^{54} \mathrm{Fe}^{+1}\right), 32 \mathrm{Da}\left({ }^{16} \mathrm{O}_{2}{ }^{+1},{ }^{96} \mathrm{Zr}^{+3}\right)$ all have significant overlaps. For binning purposes, the first ion listed (i.e. ${ }^{27} \mathrm{Al}^{+1}$ for $27 \mathrm{Da}$ ) was chosen as those had the highest atomic abundances. For bulk composition measurements, IVAS has peak deconvolution capabilities that are based on the natural isotopic abundances for each element [40, 41]. However, compositional outputs from the maximum separation method are not corrected for peak deconvolution. Previous authors have corrected individual cluster compositions for nanoscale precipitates by calculating compositional correction factors based on the ratios of IVAS bulk compositional measurements and the matrix compositions outputted within the maximum separation method file [42]. Good agreement between bulk nanoprecipitate compositional measurements and corrected individual cluster compositions were found using this method. Corresponding radii, number densities, and compositions were calculated for each APT specimen by implementing these aforementioned procedures in a MATLAB algorithm.

\subsection{Data Collection - SANS}

Two different experiments were conducted on the CG-2 General-Purpose SANS (GPSANS) beamline at the High-Flux Isotope Reactor (HFIR) at ORNL [43]. First, in-situ heating was combined with the SANS technique to study the nucleation and growth of the smallest nanoprecipitates as a function of time and temperature. In addition, magnetic SANS measurements were taken on some of the ex-situ annealed powders listed in Table 2 to provide quantitative information about the size distribution(s) of precipitates within the powders as well as the possible compositions of the smallest nanoprecipitates.

For the in-situ SANS experiment, a vacuum furnace on the CG-2 beamline was used to heat pre-packed Mo-foil powder packets $(25 \mathrm{~mm}$ diameter $\mathrm{x} 1 \mathrm{~mm}$ thick) from room temperature to $1000^{\circ} \mathrm{C}$ at a ramp rate of $20^{\circ} \mathrm{C} / \mathrm{min}$. Samples were held under vacuum $\left(\sim 10^{-5}\right.$ Torr $)$ for the duration of the experiment. The target SANS heating profile is also plotted in Fig. 2, and is slightly less than half of the heating rate seen for the extrusion can. This lower heating rate was chosen to minimize the temperature range over which the SANS measurements were taken while also allowing for more efficient temperature feedback control during ramping to the target 
temperature. Data was collected in 1 minute increments during sample anneals at either $1.5 \mathrm{~m}$ and $5 \mathrm{~m}$ detector distances, covering a scattering vector range of $0.01<\mathrm{Q}<0.6 \AA^{-1}$. Two separate powder samples were analyzed (one at each detector distance) to investigate the entirety of the $\mathrm{Q}$ range studied, and the resulting scattering intensity curves were combined during data reduction and analysis.

For the room-temperature investigation of the powder specimens annealed ex-situ, the an open bore superconducting magnet (MagH) was used to generate a magnetic field perpendicular to the incident neutron beam. This $2 \mathrm{~T}$ field was sufficient enough to fully saturate the material and align the magnetic moments of the atoms within the ODS FeCrAl material. Due to the size of the magnet, the detector distances in this configuration were limited to $10 \mathrm{~m}$ and $2 \mathrm{~m}$, respectively, with a corresponding scattering range of $0.005<\mathrm{Q}<0.2 \AA^{-1}$. For both in-situ and ex-situ SANS experiments, $4.75 \AA$ neutrons were used. The collected data was corrected for the foil sample packet, the density of the compacted powder, and background. The resulting scattering intensities were then normalized to the attenuated direct beam for the output of the differential macroscopic scattering cross-section in $\mathrm{cm}^{-1}$.

\section{Results}

\subsection{Nanoprecipitate Distributions from APT}

After annealing the mechanically alloyed CrAZY powder for 15 and $60 \mathrm{~min}$. in a $1000^{\circ} \mathrm{C}$ box furnace, significant recrystallization and grain growth is observed. Backscattered scanning electron microscopy (SEM-BSE) images indicate a highly bi-modal microstructure comprising of both fine nm-scale and coarse $\mu \mathrm{m}$-scale grains (Fig. 3). This heterogeneous grain growth has been extensively studied by previous authors [44, 45], and is attributed to abnormal grain growth phenomena arising from stored energy variations within the annealed powders after mechanically alloying. Although nanoprecipitates are expected to nucleate and grow at similar temperatures and time scales associated with this abnormal grain growth, it has been postulated by these authors that the Zener pinning effect by newly nucleated nanoprecipitates is an insufficient obstacle for grain boundary migration and subsequent grain growth during the annealing stage [44]. The primary focus of this work is not on the grain morphology and size as a function of annealing time and temperature; instead, this study focuses on the kinetics of nanoprecipitate nucleation and growth. Thus, it is of importance to identify the homogeneity of nanoprecipitates in both the fine and coarse grains so that nanoprecipitate size distributions can be compared across multiple annealed powders. Targeted APT lift-outs in both fine and coarse grain regions in the ZY10C60 sample illustrate highly homogeneous distributions of nanoprecipitates within the powder irrespective of lift-out location (Fig. 4). This result supports the results by Dawson and colleagues, where the authors found that the smallest $(\mathrm{Y}, \mathrm{Al}, \mathrm{O})$ nanoprecipitates in annealed recrystallized PM2000 powder remain well dispersed with coherency with the surrounding FeCrAl matrix [39]. From this result, it is assumed for the investigated annealed CrAZY powders in this work that nanoprecipitate dispersions are homogeneous and comparable regardless of lift-out location. Furthermore, in many of the APT reconstructed control volumes, larger $\mathrm{Zr}$-rich precipitates were also identified and are shown in purple in Fig. 4. These precipitates are also enriched primarily in either carbon or a combination of carbon and nitrogen, which indicates that the $\mathrm{Zr}$ addition in the $\mathrm{CrAZY}$ powder is sequestering interstitial impurities within the matrix. A detailed analysis of the alloying effects of $\mathrm{Zr}$ on the 
precipitation in these CrAZY alloys is beyond the scope of this study and will be addressed in a subsequent publication.

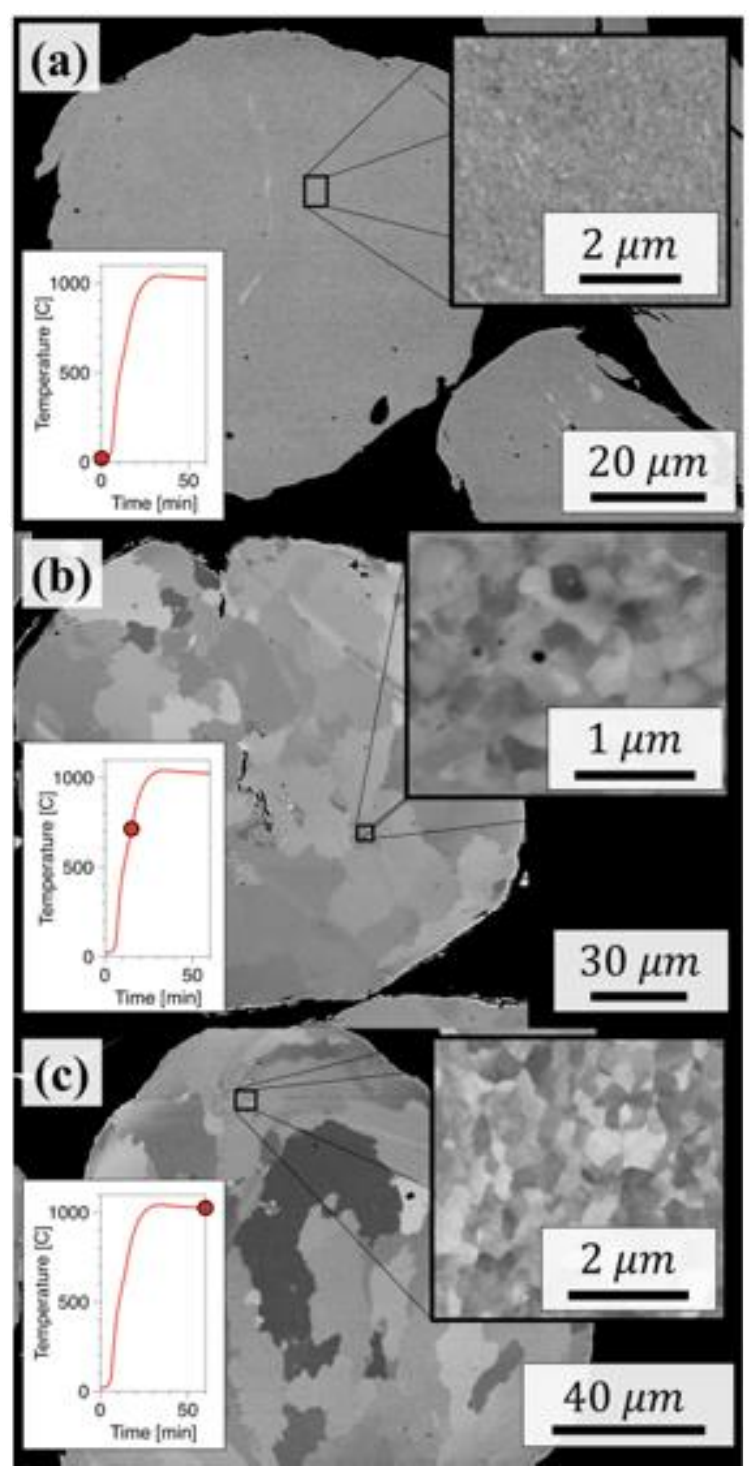

Fig. 3. SEM-BSE images of (a) the as-milled CrAZY powder $(\mathrm{ZY} 40 \mathrm{H})$, (b) powder annealed for $15 \mathrm{~min}$. at $1000^{\circ} \mathrm{C}(\mathrm{ZY} 10 \mathrm{C} 15)$, and (c) powder annealed for $60 \mathrm{~min}$. at $1000^{\circ} \mathrm{C}(\mathrm{ZY} 10 \mathrm{C} 60)$. 


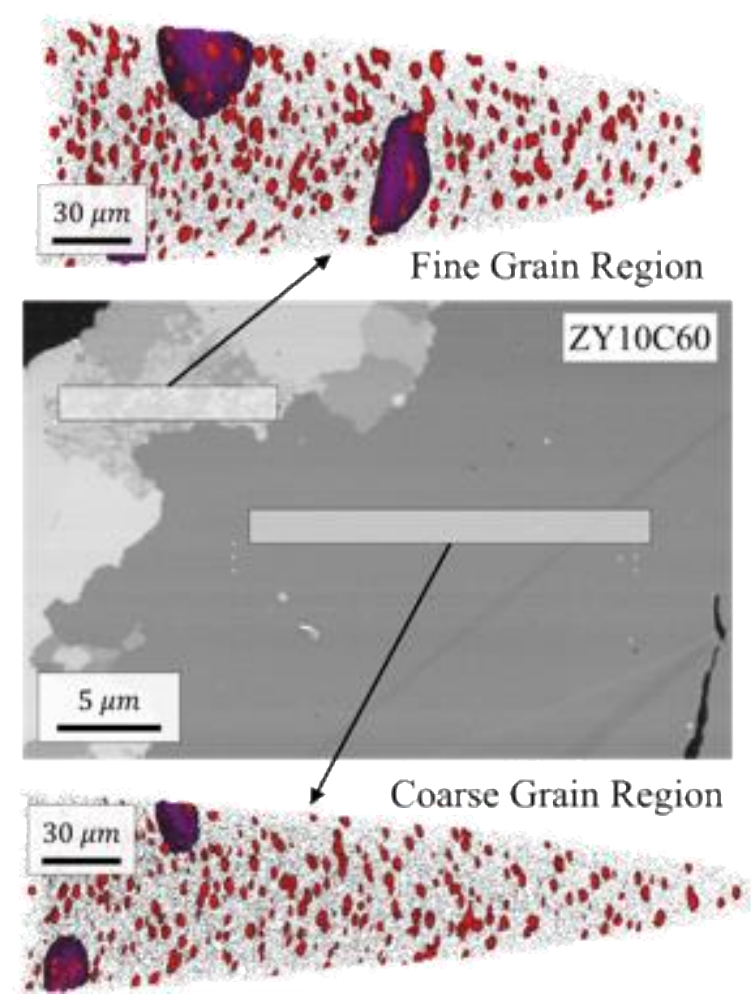

Fig. 4. Comparison of nanoprecipitate distributions in coarse and fine-grains within $\mathrm{CrAZY}$ powder annealed for $60 \mathrm{~min}$. at $1000^{\circ} \mathrm{C}$ (ZY10C60). 1.5\% (Y,Al,O) red isosurfaces indicate the smallest nanoprecipitates in the Fe-matrix (black dot) matrix. $10 \%$ purple $\mathrm{Zr}$ isosurfaces show a secondary population of larger precipitates.

The average radii, number densities, and compositions of the smallest ( $\mathrm{Y}, \mathrm{Al}, \mathrm{O})$ nanoprecipitates within the ex-situ annealed CrAZY powders identified by the APT technique are presented in Table 3. Several important trends can be identified for the various annealing schedules. First and foremost, the nanoprecipitates have nucleated and grown to stable sizes at annealing times as short as $15 \mathrm{~min}$. within a furnace held at $1000^{\circ} \mathrm{C}$, which is seen through the comparable size and number density between the ZY10C15 and ZY10C60 specimens. However, for samples annealed for $60 \mathrm{~min}$ at temperatures 1000,1050 , and $1100^{\circ} \mathrm{C}$, clear trends of increasing nanoprecipitate size and decreases in number density are noted, signifying that a transition from precipitate growth to coarsening is occurring even at short annealing times $<60$ min. The stability of nanoprecipitates at $1000^{\circ} \mathrm{C}$ up to $1 \mathrm{~h}$ and the observed coarsening of the precipitates at elevated temperatures is illustrated in Fig. 5. This is a significant result since increased temperatures are commonly used to modify the microstructure of as-fabricated ferritic ODS alloys, specifically with respect to developing recrystallized ODS FeCrAl alloys to help alleviate texture-related anisotropy in alloy mechanical properties and to improve creep resistance [46-48]. The previous use of elevated extrusion temperatures $\left(>1000^{\circ} \mathrm{C}\right)$ to increase alloy ductility [49] will also be expected to result in lower number densities of coarser nanoprecipitates, which has significant implications for irradiation resistance. Specifically for ODS FeCrAl alloys designed for lower temperature nuclear reactor operating conditions, the coarsening of precipitates during thermomechanical treatments will result in a decrease in nanoprecipitate sink strength and an increase in irradiation-induced hardening [1]. 
Table 3

Aberration Corrected APT Results. Errors are reported as one standard deviation from the mean.

\begin{tabular}{lllllllllll} 
Sample & $\mathrm{R}_{\mathrm{p}}[\mathrm{nm}]$ & $\mathrm{N}_{\mathrm{p}} \times 10^{23}\left[\mathrm{~m}^{-3}\right]$ & $\boldsymbol{f}[\%]$ & $\mathrm{Fe}$ & $\mathrm{Cr}$ & $\mathrm{Al}$ & $\mathrm{Y}$ & $\mathrm{O}$ & $\mathrm{C}$ & $\mathrm{N}$ \\
\hline ZY10C15 & $1.56 \pm 0.64$ & $4.77 \pm 1.47$ & $1.14 \pm 0.01$ & 57.90 & 6.62 & 11.76 & 11.62 & 11.43 & 0.10 & 0.02 \\
ZY10C60 & $1.58 \pm 0.61$ & $4.19 \pm 1.21$ & $1.12 \pm 0.22$ & 55.58 & 7.54 & 11.55 & 11.70 & 12.92 & 0.13 & 0.01 \\
ZY15C60 & $2.08 \pm 0.75$ & $1.11 \pm 0.18$ & $0.86 \pm 0.21$ & 57.01 & 8.41 & 11.73 & 9.59 & 12.51 & 0.18 & 0.01 \\
ZY15C10h & $2.16 \pm 0.65$ & $1.79 \pm 0.01$ & $0.95 \pm 0.05$ & 58.53 & 8.87 & 11.41 & 10.60 & 9.35 & 0.29 & 0.04 \\
ZY15C50h & $2.82 \pm 1.16$ & $0.58 \pm 0.01$ & $0.83 \pm 0.02$ & 51.24 & 7.77 & 11.07 & 13.43 & 15.38 & 0.25 & 0.02 \\
ZY15C500h & $4.07 \pm 1.21$ & $0.12 \pm 0.03$ & $0.47 \pm 0.04$ & 60.89 & 7.11 & 8.39 & 9.40 & 11.88 & 0.18 & 0.01 \\
ZY11C60 & $2.58 \pm 0.85$ & $0.79 \pm 0.05$ & $0.71 \pm 0.12$ & 54.63 & 7.84 & 11.16 & 12.92 & 12.48 & 0.17 & 0.01 \\
\hline
\end{tabular}

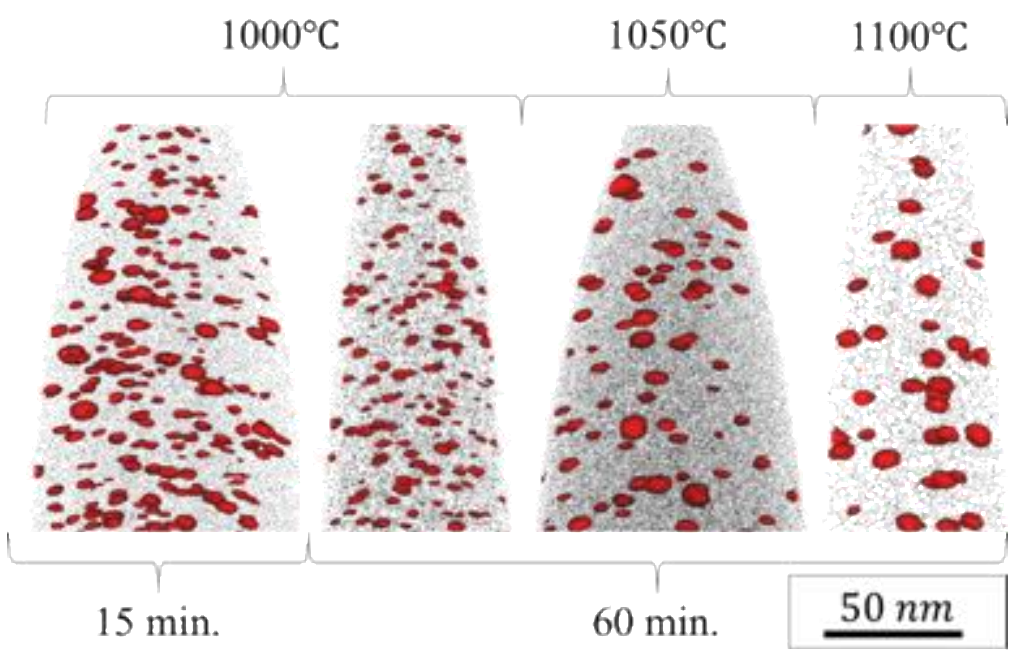

Fig. 5. APT reconstructions of ZY10C15, ZY10C60, ZY15C60, and ZY11C60 (left to right) with $1.5 \%(\mathrm{Y}, \mathrm{Al}, \mathrm{O})$ isoconcentration surfaces within a matrix of $\mathrm{Fe}$ atoms (black dots representing $0.1 \%$ of measured matrix atoms).

For all specimens, a consistently high level of $\mathrm{Fe}$ and $\mathrm{Cr}$ was measured within each nanoprecipitate even though the only statistically significant clustering found using the maximum separation method were atoms of $\mathrm{Y}, \mathrm{Al}$, and $\mathrm{O}$. The increased $\mathrm{Fe}$ and $\mathrm{Cr}$ components of the nanoprecipitate compositions are attributed to trajectory aberrations associated with differences between the energy required to field evaporate atoms from the precipitates and the surrounding matrix [50-52]. In an attempt to correct for these compositional artifacts, the point density of atoms across the precipitates was calculated using 1D concentration profiles through multiple precipitates within each sample. For samples annealed for $1 \mathrm{~h}$ or less, point density increases were noted across the precipitates $1.5 \times$ the point density in the surrounding matrix. For the extended temperature anneals at $1050^{\circ} \mathrm{C}$, the precipitate point density increased from 1.5$2.2 \times$ the matrix point density at annealing times increasing from 10-500h. Although the presumption that the atomic density is equivalent for the precipitates and the FeCrAl matrix depends on the size and coherency of the nanoprecipitates and that this assumption will become less valid as the precipitates significantly coarsen and lose coherency with the matrix [23, 39], it is assumed for the purposes of compositional correction that the increased atomic density across the precipitate is a result of trajectory aberration artifacts from the APT technique irrespective of 
annealing time/temperature. The equivalent number of matrix atoms, proportional to the matrix FeCrAl composition, were then subtracted from the precipitate atoms and the aberration corrected cluster compositions were calculated. Even after correcting for trajectory aberrations, it is clearly seen in Table 3 that significant $\mathrm{Fe}$ and $\mathrm{Cr}$ components remain in the nanoscale precipitates, suggesting that at least some $\mathrm{Fe}$ and $\mathrm{Cr}$ may be present in the nanoprecipitates to stabilize the nanoprecipitates [53].

\subsection{SANS for Ex- and In-Situ Annealed Specimens}

Small angle neutron scattering data is commonly interpreted using the generalized expression:

$\left[\frac{d \Sigma}{d \Omega}(q)\right]_{m, n}=\int_{0}^{\infty} \Delta \rho_{m, n}^{2} N(R) \Phi(q, R)^{2} S\left(q, R_{H S}, \gamma_{H S}\right) d R \ldots \ldots \ldots \ldots \ldots \ldots \ldots \ldots \ldots \ldots \ldots \ldots \ldots$ (Eq. 3$)$

where $\Delta \rho_{m, n}^{2}$ is the magnetic (m) or nuclear (n) scattering contrast, $N$ is the number density of scattering objects as a function of size, $\Phi^{2}$ is the geometry dependent form factor, and $S$ is the structure factor that takes into consideration multiple scattering events (interference effects) based on the distribution of scattering objects. For an in-depth description of the SANS technique and its applications in materials science, the reader is referred elsewhere [54-56]. However, operational definitions of the parameters in Eq. 3 still need to be defined for the analysis of the reported SANS data. The scattering contrast is defined as the squared difference of the scattering length densities -- the ratio of the neutron scattering length $(b)$ and the atomic volume $(\Omega)$-- between the nanoprecipitates (NP) and the surrounding matrix [57] and is provided below in Eq. 4. The SANS technique relies on the requirement that the scattering length densities vary enough between the precipitates and the matrix so that the scattering objects are resolvable.

$\Delta \rho^{2}=\left[\rho_{m a t}-\rho_{N P}\right]^{2}=\left[\frac{b_{m a t}}{\Omega_{m a t}}-\frac{b_{N P}}{\Omega_{N C}}\right]^{2}$

The number density of scattering objects (in this case the nanoprecipitates) is highly coupled and inversely correlated with the scattering contrast. The choice of how to approximate the shape of the scattering object size distribution is largely up to the author. Different size distribution shapes such as the Weibull [58] and lognormal [59] distributions have previously been used by authors, but the use of linear or cubic splines have also become popular due to their continuity and versatility for a variety of distribution shapes $[60,61]$. For the SANS fitting in this work, the number density was assumed to follow a lognormal shape since this distribution fit the measured APT data better than either a normal or Weibull distribution.

Though some authors have seen a cubic or faceted morphology for the smallest (Y,Al,O) nanoprecipitates in ODS FeCrAl alloys like PM2000 [39], the form factor describing the geometry of these nanoscale scattering objects is most commonly assumed to be one developed for spherical precipitates $[45,59]$ and is a function of scattering vector " $q$ " and scattering object radius " $R$ ". Some authors separate out the precipitate volume (assumed to be the volume of a sphere), but since the form factor is already parametrized with respect to $\mathrm{R}$, in this work the form factor is defined to include the volume term for fitting purposes. Thus, the form factor is: 
$\Phi(q, R)^{2}=\left\{3 V\left[\frac{\sin (q R)-q R \cos (q R)}{(q R)^{3}}\right]\right\}^{2}$

The structure factor used is from the local monodispersed spheres approximation previously described by Pedersen [61], which is a function of a hard sphere interaction radius $\left(R_{H S}=C R\right)$ and a hard sphere volume fraction $\left(\eta_{H S}\right)$. The product of these terms in (Eq. 3) results in an equation with five unknown parameters for fitting: (1) the product between the number density and scattering contrast $\left(N \Delta \rho^{2}\right)$, the parameters (2) $\mu$ and (3) $\sigma$ from the lognormal distribution, and the hard sphere parameters (4) $C$ and (5) $\eta_{H S}$. The first term $N \Delta \rho^{2}$ was fit as one parameter due to the highly coupled and inverse relationship between the two values. Nonlinear least squares curve fitting was implemented in MATLAB after subtracting a power-law background fit to the low-Q portion of the scattering curve. The number density (Eq. 6) was then calculated using the relationship between the relationship between the hard sphere and the actual precipitate radii and volume fraction reported in [58]:

$N_{p}=\frac{\eta}{4 / 3 \pi R^{3}}$

where the precipitate volume fraction $(\eta)$ is:

$f=\eta_{H S} /\left(\frac{R_{H S}}{R}\right)^{3}$

\section{Table 4}

SANS parameters calculated using nonlinear least squares curve fitting. Also reported are the averaged A-ratios over the $\mathrm{q}$ range specified within one standard deviation from the mean.

\begin{tabular}{lllllllll}
\hline Sample & Q range $\left[\AA^{-1}\right]$ & $\mathrm{R}_{\mathrm{p}}[\mathrm{nm}]$ & $\boldsymbol{\Delta} \boldsymbol{\rho}_{\boldsymbol{m}}\left[\AA^{-4}\right]$ & $\mathrm{N}_{\mathrm{p}}\left[\mathrm{m}^{-3}\right]$ & $\boldsymbol{f}[\%]$ & $\boldsymbol{\mu}$ & $\boldsymbol{\sigma}$ & A-Ratio \\
\hline ZY10C15 & $0.05<\mathrm{q}<0.2$ & 1.47 & $2.03 \times 10^{-11}$ & $1.24 \times 10^{24}$ & 1.64 & 2.7 & 0.2 & $2.2 \pm 0.3$ \\
& $0.02<\mathrm{q}<0.05$ & 79.1 & $1.45 \times 10^{-11}$ & $1.83 \times 10^{21}$ & 0.38 & 4.3 & 0.1 & $1.9 \pm 0.2$ \\
ZY10C30 & $0.05<\mathrm{q}<0.2$ & 1.46 & $2.15 \times 10^{-11}$ & $1.09 \times 10^{24}$ & 1.41 & 2.7 & 0.2 & $2.2 \pm 0.4$ \\
& $0.02<\mathrm{q}<0.05$ & 83.9 & $1.01 \times 10^{-11}$ & $1.06 \times 10^{21}$ & 0.26 & 4.4 & 0.1 & $1.7 \pm 0.1$ \\
ZY10C60 & $0.05<\mathrm{q}<0.2$ & 1.45 & $2.75 \times 10^{-11}$ & $1.06 \times 10^{24}$ & 1.33 & 2.6 & 0.2 & $2.2 \pm 0.3$ \\
& $0.02<\mathrm{q}<0.05$ & 86.0 & $0.45 \times 10^{-11}$ & $2.25 \times 10^{21}$ & 0.60 & 4.4 & 0.1 & $1.5 \pm 0.1$ \\
ZY10C120 & $0.05<\mathrm{q}<0.2$ & 1.54 & $2.01 \times 10^{-11}$ & $1.00 \times 10^{24}$ & 1.54 & 2.7 & 0.2 & $2.1 \pm 0.4$ \\
& $0.02<\mathrm{q}<0.05$ & 101.7 & $0.52 \times 10^{-11}$ & $1.60 \times 10^{21}$ & 0.70 & 4.6 & 0.1 & $1.4 \pm 0.1$ \\
\hline
\end{tabular}

The summary of the SANS nonlinear least squares curve fits for CrAZY powders annealed for $15,30,60$, and 120 minutes within a box furnace held at $1000^{\circ} \mathrm{C}$ are tabulated in Table 4. For these powders annealed ex-situ, deconvolution of the magnetic and nuclear scattering components was possible, and the fitting procedure was used to fit the magnetic scattering data. The local monodispersed approximation identified two populations of nanoprecipitates within all 4 samples: a population of smaller nanoprecipitates with diameters 
ranging from 2-4 $\mathrm{nm}$ and another with diameters ranging from 8-20 nm, suggesting a slightly bimodal distribution of precipitate sizes. However, the population of slightly larger nanoprecipitates has a corresponding number density 3 orders of magnitude smaller than the smallest nanoclusters and are of less importance in the context of sink strength optimization in nuclear environments. The scattering intensity curves were highly similar in both shape and intensity across all 4 samples, indicating highly consistent powder sample preparation and precipitate dispersion characteristics. The magnetic scattering curve for ZY10C15 is illustrated in Fig. 6(a) with the corresponding total fit, the power law background, and the two scattering components for the larger and smaller precipitates. Also illustrated in Fig. 6(b) are the corresponding lognormal size distributions, showing good agreement between the estimated SANS precipitate distribution and the data measured using the APT technique.

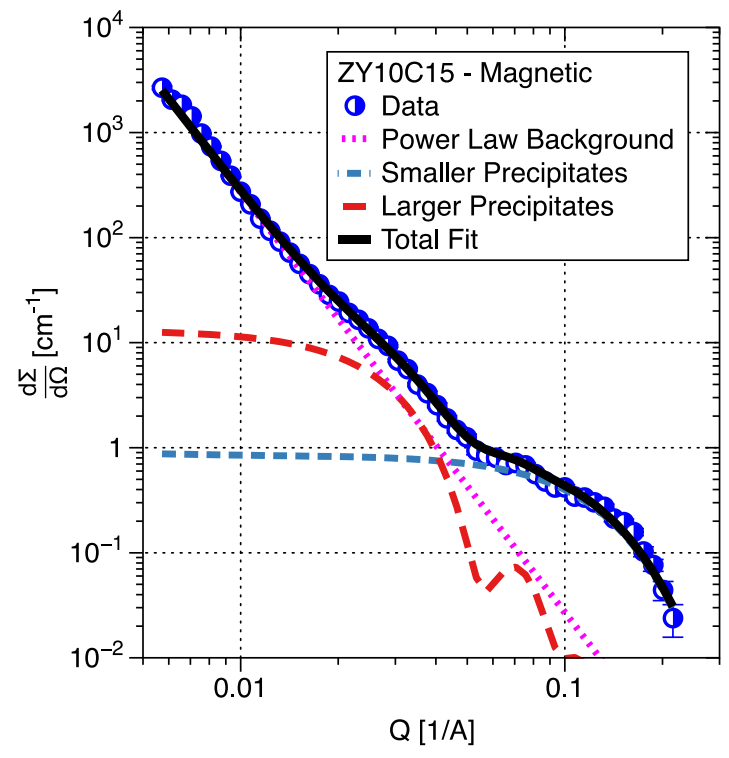

(a)

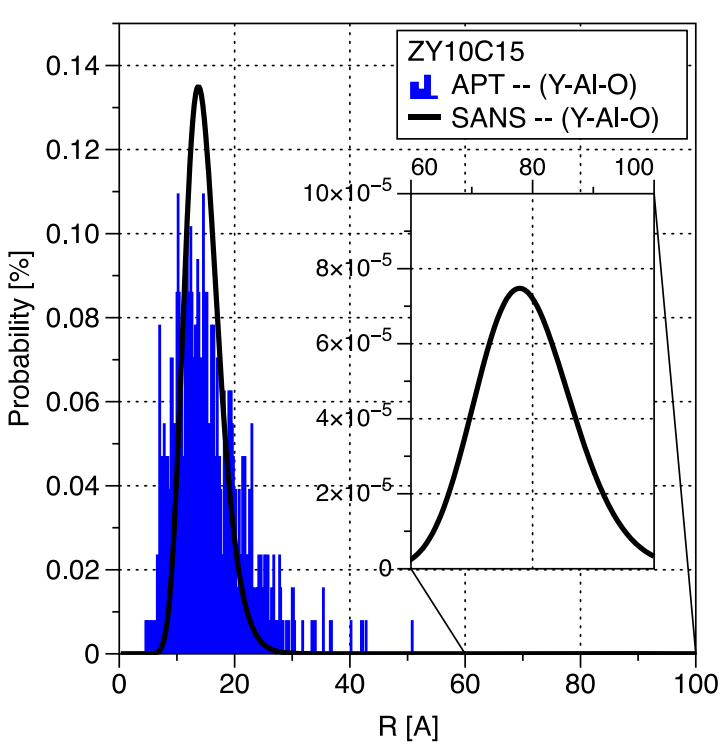

(b)

Fig. 6. (a) Magnetic scattering data for ZY10C15 with overlaid curve fits and (b) a comparison of the nanoprecipitate size distributions between magnetic SANS and APT results (0.2 nm bins).

In addition to estimating the nanoprecipitate sizes and number densities, the use of the external magnetic field to separate nuclear and magnetic scattering components also allows for the possibility to investigate the compositions of the identified nanoprecipitates. In the presence of a fully saturated magnetic field applied perpendicularly to the neutron beam, the relation between nuclear and magnetic scattering components is related to the azimuthal angle $(\phi)$ on the detector plane through Eq. 8 [62]. Furthermore, if one considers this definition and takes the ratio between the scattering intensities, a relationship between the magnetic and nuclear scattering contrast is derived (Eq. 9).

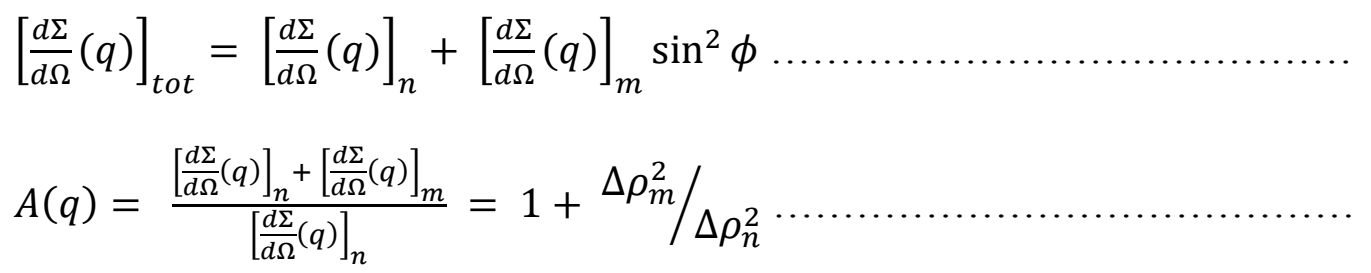


The value on the left of the equal sign in Eq. 9 is commonly referred to as the A-ratio [52] and sometimes as the R-ratio [62]. Since the A-ratio is a function only of the scattering contrasts, significant insights into the magnetic nature (and thus the composition of the nanoprecipitates) can be inferred from the average of this A-ratio over the q-range where nanoprecipitates are identified. A-ratios for the scattering vector ranges of interest are listed as well in Table 4.

Both the APT and SANS results illustrate the same trend for the CrAZY powders annealed ex-situ: the nanoprecipitates nucleate and grow at temperatures well below the target temperatures commonly used for ODS alloy consolidation. In fact, identical size distributions existed for powders annealed for either $15 \mathrm{~min}$ or $120 \mathrm{~min}$. in a furnace held at $1000^{\circ} \mathrm{C}$. Thus, in addition to the use of magnetic SANS on CrAZY powders annealed ex-situ for comparison with APT results, additional SANS measurements were conducted in-situ on the as-mechanically alloyed powder heated to $1000^{\circ} \mathrm{C}$ at a $20^{\circ} \mathrm{C} / \mathrm{min}$ ramp rate in an attempt to capture the nucleation and growth kinetics of the nanoprecipitates during alloy consolidation. Due to the size of the vacuum furnace used for the in-situ annealing experiment, constraints did not permit for the additional placement of a surrounding magnet; consequently, magnetic and nuclear scattering deconvolution was unable to be performed on the in-situ scattering data. Regardless, the raw data provides important insights into the beginning stages of nanoprecipitate nucleation and growth during the heating of the ODS FeCrAl powder.

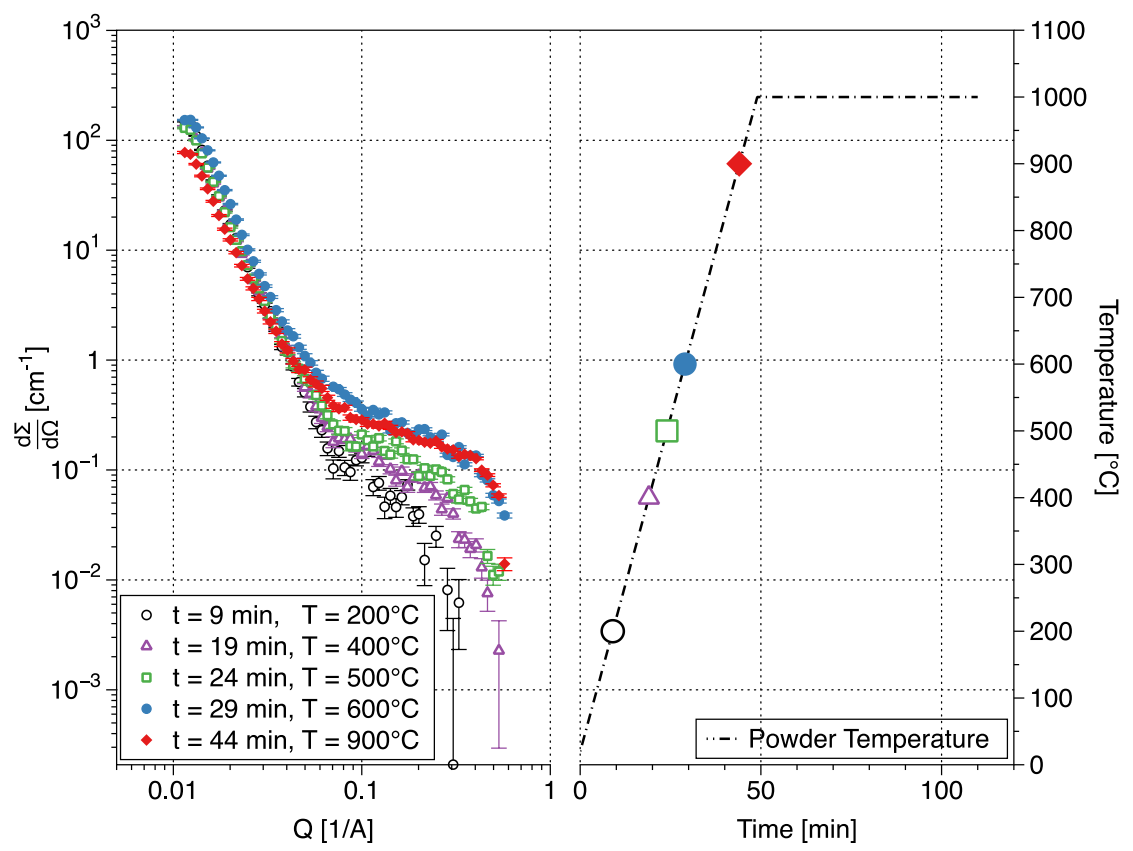

Fig. 7. Neutron scattering intensity curves for powder heated from room temperature to $1000^{\circ} \mathrm{C}$ at $20^{\circ} \mathrm{C} / \mathrm{min}$.

Fig. 7 presents scattering curves collected in 1 minute intervals at various temperatures as the powder is being heated. At room temperature, essentially no scattering was measured above the detectable limit of the detector, so the initial point illustrated for comparison is the scattering of the powder at $200^{\circ} \mathrm{C}$. For comparison of the various temperatures highlighted in Fig. 7, the symbol used to plot the scattering intensities at each temperature is also plotted on the temperature profile that corresponds with the scattering intensity curve on the left. Scattering 
curves at temperatures exceeding $900^{\circ} \mathrm{C}$ are not shown because no differences in the scattering curves were observed above this point. This figure illustrates some major insights into the nucleation and growth of precipitates within as-milled ODS FeCrAl powder. In the scattering vector range exceeding $0.03 \AA^{-1}$, the total scattering intensity steadily increases as the temperature increases from $200-600^{\circ} \mathrm{C}$, indicating that the nanoprecipitates are nucleating and growing at much lower temperatures than the target consolidation temperature. Further growth past $600^{\circ} \mathrm{C}$ was difficult to observe due to a loss in magnetic scattering around $700^{\circ} \mathrm{C}$, consistent with the tabulated curie temperature for Fe. The scattering intensity at low-Q is slightly lower for the $900^{\circ} \mathrm{C}$ temperature, again consistent with the loss of the magnetic scattering component above the curie temperature; however, the scattering curve retains its shape at high- $\mathrm{Q}$ and remains unchanged, indicating that growth has ceased around $600^{\circ} \mathrm{C}$. This result agrees with the ex-situ annealed powders. Based on the thermocouple measurement of the packed CrAZY powder within an extrusion can held in a box furnace for $60 \mathrm{~min}$ Fig. 2, the corresponding temperature that the ZY10C15 sample reached during its ex-situ anneal is approximately $715^{\circ} \mathrm{C}$. Since the in-situ results indicate that the nucleation and growth has completed prior to this temperature, it is unsurprising that the ZY10C15 and the ZY10C60 samples show identical size distributions and number densities if the $1000^{\circ} \mathrm{C}$ temperature is insufficient to coarsen the established precipitate population.

\section{Discussion}

\subsection{Investigating Nanoprecipitate Compositions}

Using the combined APT and SANS data, it is of interest to determine the compositions of the (Y,Al,O) nanoprecipitates that these ODS FeCrAl alloys use for Zener pinning and radiation resistance. Specifically it is of interest from a radiation damage perspective as to whether these nanoprecipitates are a specific phase since different phases may have different resistances to radiation damage [63]. Comparing the ratio of $\mathrm{Y}$ to $\mathrm{Al}$ atoms within observed nanoprecipitate populations with expected stochiometric ratios for equilibrium (Y,Al,O) phases show interesting trends as a function of time and temperature. As Fig. 8 illustrates, there appears to be a significant size dependence in the Y/Al ratio within the nanoprecipitates. At small precipitate sizes ( $<3 \mathrm{~nm}$ dia.) significant variations in the Y/Al ratio is observed. This is either due to artifacts pertaining to the selective inclusion/omission of surrounding atoms for small precipitate sizes when applying the maximum separation method, or it could represent the stochastic nature by which diffusing atoms arrive at growing precipitate nuclei at the initial stages of nucleation and growth. The more important trends are those for nanoprecipitate sizes near the average ( 2-4 $\mathrm{nm}$ in radius). As Fig. 8(a) shows, for precipitates nucleated in samples annealed for only $1 \mathrm{~h}$ at various temperatures, more significant deviations from expected phases exist as the annealing temperature decreases. In fact, it appears that the sample annealed at $1100^{\circ} \mathrm{C}$ for $1 \mathrm{~h}(\mathrm{ZY} 11 \mathrm{C} 60)$ tends toward a composition congruent with the YAG phase, while specimens ZY10C60 and ZY15C60 underestimate the Y content required for this composition. Since the growth of these precipitates is expected to be rate limited by the diffusion of $Y$ through the $\mathrm{FeCrAl}$ matrix, this increase in $\mathrm{Y} / \mathrm{Al}$ ratio as a function of time/temperature is expected. For extended temperature anneals at $1050^{\circ} \mathrm{C}$, there appears to be a significant change in the $\mathrm{Y} / \mathrm{Al}$ ratio as a function of annealing time from $1-500 \mathrm{~h}\left(\mathbf{F i g . ~ 8 ( b ) )}\right.$. By $500 \mathrm{~h}$ at $1050^{\circ} \mathrm{C}$, the compositions of the smallest precipitates match closely the YAG composition. As the time 
increases to $500 \mathrm{~h}$, there appears to be a tendency for the larger precipitates to transition to the YAP composition.

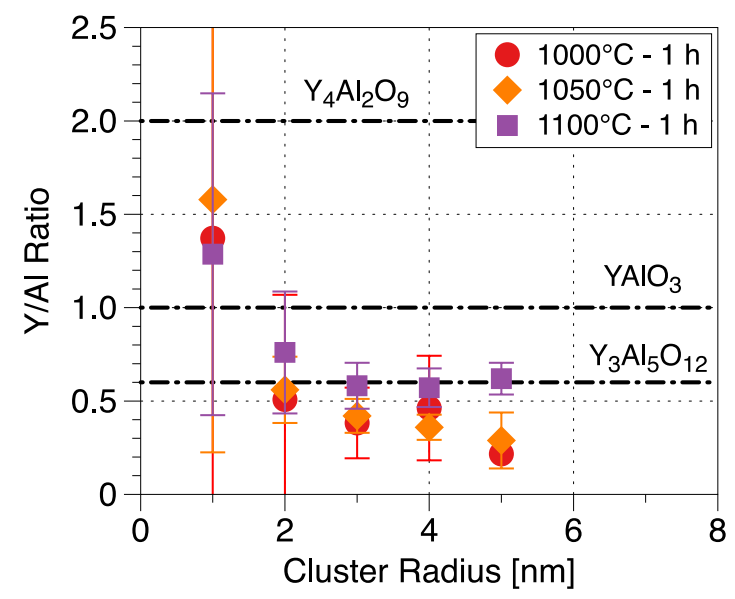

(a)

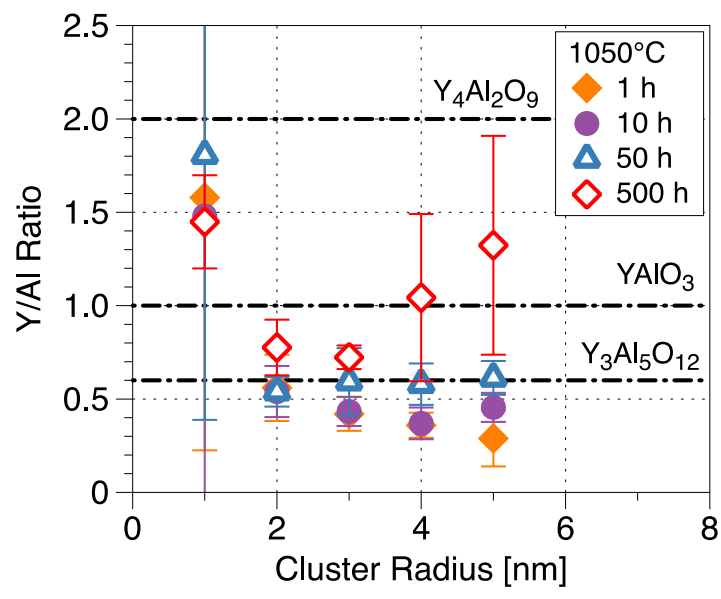

(b)

Fig. 8. Size dependence of $(\mathrm{Y}, \mathrm{Al}, \mathrm{O})$ cluster compositions measured by APT for (a) $1 \mathrm{~h}$ anneals at 1000,1050 , and $1100^{\circ} \mathrm{C}$, and for (b) extended temperature anneals at $1050^{\circ} \mathrm{C}$. Error bars depicted illustrate one standard deviation from the mean value.

In all APT reconstructions, significant $\mathrm{Fe}$ and $\mathrm{Cr}$ contents have been measured in the precipitates even after correcting for trajectory aberrations. For short annealing times at the lower annealing temperature (i.e. $15 \mathrm{~min}$. at $1000^{\circ} \mathrm{C}$ ), this may be expected due to possible stabilization of the structure by matrix atoms; however, the presence of significant $\mathrm{Fe}$ and $\mathrm{Cr}$ in the $\mathrm{CrAZY}$ powder annealed for $500 \mathrm{~h}$ at $1050^{\circ} \mathrm{C}$ would not be expected since at these extended annealing durations the coarsening would be expected to drive a sufficient flux of $\mathrm{Y}, \mathrm{Al}$, and $\mathrm{O}$ to the precipitates to result in a stochiometric composition without substantial $\mathrm{Fe}$ and $\mathrm{Cr}$.

To further investigate the compositions of these precipitates, the ex-situ SANS results were considered. Comparing the A-ratios and the magnetic scattering contrast calculated through the SANS data fits provide insight into the magnetic nature (and thus the Fe content) within the (Y,Al,O)-rich nanoprecipitates. The A-ratio is a function of the nuclear and magnetic scattering contrast. The magnetic scattering of ideal (Y,Al,O) nanoprecipitates should be zero since none of these elements are magnetic. Thus, the magnetic scattering contrast should only be equal to the magnetic scattering of the matrix, which is calculated as $\left(1.26 \times 10^{-11} \mathrm{~A}^{-4}\right)$ using the $\mathrm{FeCrAl}$ composition of the CrAZY powder as an input into the relations outlined in [64]. The second variable for calculation is the nuclear scattering contrast, which has been previously defined in Eq. 4 as the squared difference in scattering length densities between the matrix and the precipitates (assuming a given precipitate composition). The scattering contrast calculator developed by the NIST Center for Neutron Research was used to calculate the nuclear scattering contrast by supplying the composition and the mass density for the phase of interest [65]. For the FeCrAl matrix, the measured mass density of as-consolidated CrAZY bars is $\sim 7.2 \mathrm{~g} / \mathrm{cm}^{3}$, the composition is provided in Table $\mathbf{1}$, and the resulting scattering length density is $6.82 \times 10^{-6} \mathrm{~A}^{-2}$. Assuming ideal mass densities for the YAG $\left(4.56 \mathrm{~g} / \mathrm{cm}^{3}\right)$ and YAP $\left(5.33 \mathrm{~g} / \mathrm{cm}^{3}\right)$ phases with no Fe content within the precipitates, the average A-ratios are calculated to be 5.2 and 9.5 for YAG and YAP, respectively. These values are substantially higher than those reported in Table 4. 
The deviation in A-ratio from expected stochiometric compositions may be explained by considering how changes in composition will affect the parameters in Eq. 4 and Eq. 9. It was assumed previously based on high resolution microscopy of nanoprecipitates in ODS FeCrAl alloys that the atomic density across the nanoprecipitates remains constant in comparison to the surrounding matrix. This assumption directly affects the interpretation of the A-ratio since the atomic volume of the (Y,Al,O) phase must be assumed equal to the atomic volume of the surrounding $\mathrm{FeCrAl}$ matrix. For the $\mathrm{CrAZY}$ powders annealed for only 15-120 minutes at $1000^{\circ} \mathrm{C}$, this assumption is expected to be valid due to the limited coarsening observed in this time/temperature range. With a calculated atomic volume of 83 atoms $/ \mathrm{nm}^{3}$ for the $\mathrm{FeCrAl}$ matrix, this results in an artificially lower mass density of $4.09 \mathrm{~g} / \mathrm{cm}^{3}$ for YAG and $4.52 \mathrm{~g} / \mathrm{cm}^{3}$ for the YAP phase. This decreases the calculated A-ratios to 3.5 (YAG) and 3.9 (YAP). Still, the calculated A-ratios are still higher than those measured.

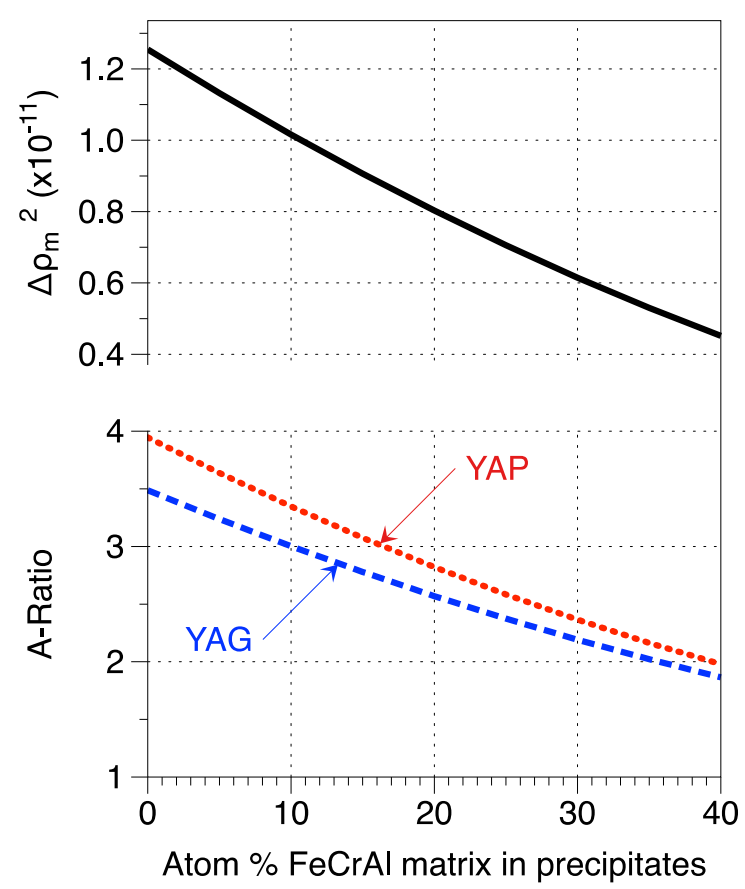

Fig. 9. Calculated A-ratio and magnetic scattering contrast for select (Y,Al,O) stochiometric compositions as a function of assumed matrix fraction within a the nanoprecipitate.

A further consideration of Fe content in the precipitates may account for this discrepancy. To simulate the scattering length densities for defective-type structures nucleating in a $\mathrm{FeCrAl}$ matrix, the nuclear scattering length densities for the $(\mathrm{Y}, \mathrm{Al}, \mathrm{O})$ phase was calculated assuming a certain percentage of $\mathrm{FeCrAl}$ in the precipitates proportional to the matrix composition. For a consideration of the magnetic scattering contrast, since the ex-situ magnetic SANS measurements were collected at room temperature, it is assumed that a simple rule of mixtures rule can apply where a proportional increase in magnetic contrast will occur from increasing fractions of the FeCrAl matrix phase within the (Y,Al,O) precipitates. The result is a continuously decreasing A-ratio with increased Fe component in the nanoprecipitates (Fig. 9). For both the YAG and YAP compositions, a substantial (>35 at.\% FeCrAl) matrix component within the precipitates is required to lower the A-ratio to the measured values $(\sim 2)$, which agrees well with the significant $\mathrm{Fe}$ and $\mathrm{Cr}$ contents within the precipitates in APT specimens after 
aberration correction; however, the results of the SANS fitting in Table 4 indicates the opposite trend. The computed scattering contrasts are on the order of $10^{-11} \mathrm{~A}^{-4}$, which would be consistent with non-magnetic scattering objects in a magnetic matrix. Since the number density is inversely correlated with the scattering contrast, lowering the scattering contrast to agree with some magnetic components being present in the precipitates would increase the number density to a value on the order of $10^{25} \mathrm{~m}^{-3}$, which is well above the number densities reported for similar ODS FeCrAl alloys in the literature [22, 39,44]. The combined APT and SANS results suggest a non-magnetic, defective structure with $(\mathrm{Y}, \mathrm{Al}, \mathrm{O})$ contents approaching the compositions that would be expected for the YAG type phase, with a possible transition to the YAP type phase as precipitates coarsen at higher temperatures. However further work, including high resolution transmission electron microscopy, is currently being performed to better identify the structure of these $(\mathrm{Y}, \mathrm{Al}, \mathrm{O})$ precipitates to confirm these observations.

\subsection{Quantifying Nanoprecipitate Coarsening Kinetics}

It is well documented in the literature that a strong correlation exists between consolidation temperature and the nanoprecipitate dispersion characteristics in ODS alloys [23, $59,66]$. As the extrusion temperature increases, the average precipitate size increases while the number density decreases. This trend is characteristic of precipitate coarsening through Ostwald ripening, where the larger precipitates grow at the expense of smaller precipitates to minimize the interfacial energy at the precipitate/matrix boundary [67]. In fact, the same trend is realized in this work, where samples annealed for 60 minutes at $1000-1100^{\circ} \mathrm{C}$ show an increasing radius $(1.7-2.8 \mathrm{~nm})$ and a decreasing number density $\left(3.6-0.8 \times 10^{23} \mathrm{~m}^{-3}\right)$.

The theory of particle coarsening has been extensively reviewed by multiple authors [6871], and is most commonly analyzed with respect to the Lifshitz-Slyozov-Wagner (LSW) theory of coarsening $[72,73]$. In the LSW theory formulation, particle coarsening in a supersaturated matrix is assumed to be rate limited by the bulk diffusion of solute through the matrix, and results in a precipitate size vs. time relationship where $R^{3} \propto t$. Since then, multiple authors have expanded on the LSW theory to extend the formulation to various other limiting mechanisms for particle growth. More specifically, it has been shown that particle coarsening more generally follows the power law relationship $[69,74]$ :

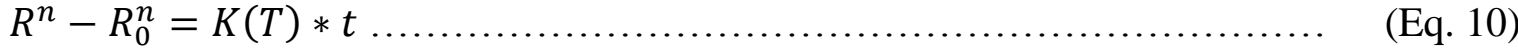

where $R_{0}$ is the initial precipitate radius, $K(T)=k * \exp (-Q / R T)$ is a constant exponentially dependent on the temperature, $\mathrm{R}$ is the universal gas constant, $\mathrm{T}$ is the absolute temperature, and $\mathrm{n}$ is the power law exponent that describes the dominant mechanism controlling particle coarsening. $\mathrm{Q}$ is the activation energy for particle coarsening mechanism and takes into consideration the temperature dependence of both the diffusion mechanism and the solubility of the rate limiting solute diffusing through the matrix.

In the case of precipitates limited by the rate at which solute atoms are incorporated into the precipitate at the particle/matrix interface, $n=2$ [67], whereas if the rate limiting step is the rate at which solute atoms diffuse in the matrix, $n=3$ [68]. However, in cases where the precipitates are faceted in shape and are not completely spherical it is also possible for the rate limiting step to be interface dominated through the incorporation of solute atoms at the kinks and ledges associated with the precipitate interface geometry, resulting in $n=3$ kinetics as well [75]. 
Rate limiting cases have also been derived for precipitate coarsening through solute diffusion along grain boundaries $(n=4)[76,77]$ and for cases where diffusion along dislocations dominates $(n=5)$ [77]. If dislocation detachment and subsequent climb is taken into consideration, the exponent has been shown to increase to even higher orders $(n=6)$ [78]. In short, the temporal power law exponent can give important insights into the coarsening mechanism for Ostwald ripening.

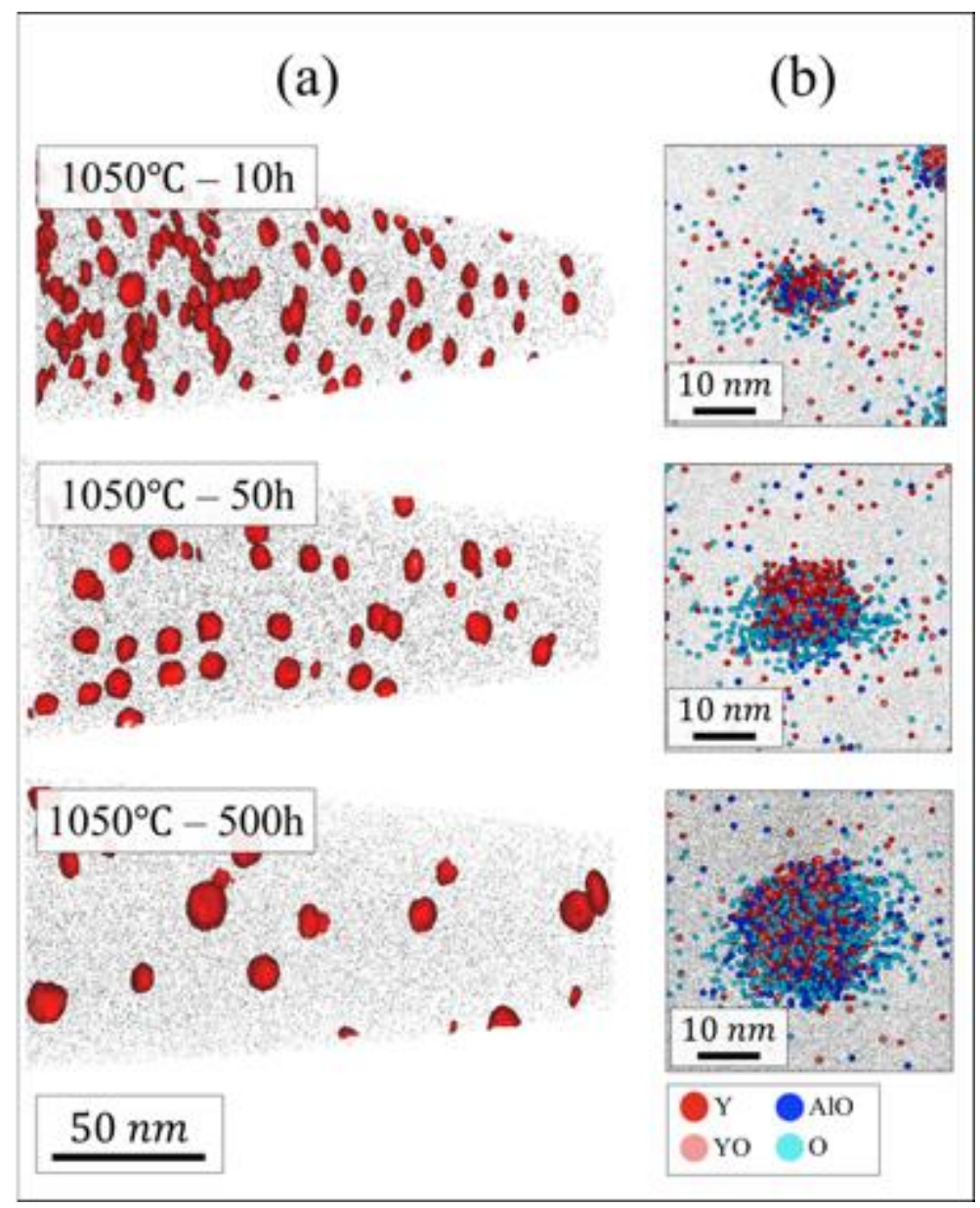

Fig. 10. (a) APT control volumes illustrating 1.5 at. \% $(\mathrm{Y}, \mathrm{Al}, \mathrm{O})$ isoconcentration surfaces and the coarsening of these nanoscale precipitates from $10-500 \mathrm{~h}$ at $1050^{\circ} \mathrm{C}$, and $(\mathrm{b})$ representative clusters with identical scale bars to illustrate similarities in cluster characteristics. Black dots in the background represent $0.1 \%$ and $100 \%$ of identified Fe matrix atoms for (a) and (b), respectively.

The observed Ostwald ripening phenomenon is qualitatively illustrated in Fig. 10 for CrAZY powders annealed for either 10,50 , or $500 \mathrm{~h}$ at $1050^{\circ} \mathrm{C}$. Atom probe tomography reconstructions of these control volumes show the decrease in the number density of the $(\mathrm{Y}, \mathrm{Al}, \mathrm{O})$ rich nanoprecipitates, the increase in radius, and the associated increase in the interparticle spacing (Fig. 10(a)). Also illustrated are atom maps for the $\mathrm{Y}, \mathrm{YO}, \mathrm{AlO}$, and $\mathrm{O}$ ionic species for representative precipitates in each of these APT specimens. All specimens indicated the same homogeneous distribution of precipitates for each ageing condition. As has been performed for dispersion strengthened $\mathrm{FeCr}[74,79,80]$ and $\mathrm{FeCrAl}[81]$ alloys in previous 
studies, the long term ageing of these CrAZY powders at $1050^{\circ} \mathrm{C}$ are coupled with the short term ageing of the same powders at 1000 and $1100^{\circ} \mathrm{C}$ to provide insights into the coarsening kinetics of the smallest nanoprecipitates in these characteristic temperature regimes commonly used for alloy consolidation.

From the general power law expression for coarsening (Eq. 10), taking the natural logarithm of both sides of the equation results in a useful form of the expression:

$\ln \left(R^{n}-R_{0}^{n}\right)=\ln (k)-(Q / R T)+\ln (t)=C+\ln (t)$

where the resulting plot of $\ln \left(R^{n}-R_{0}^{n}\right)$ vs $\ln (t)$ should result in a slope of 1 for the value of $n$ that most closely represents the dominant coarsening mechanism. For the CrAZY powder annealed at $1050^{\circ} \mathrm{C}$ for up to $500 \mathrm{~h}$, the corresponding logarithmic plot is illustrated in Fig. 11(a). The power law exponent that results in a slope of $m=1$ is that for $n=6$. Although extended $500 \mathrm{~h}$ anneals were not performed on the $1000^{\circ} \mathrm{C}$ or $1100^{\circ} \mathrm{C}$ temperatures due to material and time constraints, it is a reasonable assumption that the underlying mechanism for particle coarsening at these temperatures is identical to the $1050^{\circ} \mathrm{C}$ case due to the similar coarsening kinetics observed in previous works for ODS $\mathrm{FeCr}(\mathrm{n}=5,6)$ and $\mathrm{FeCrAl}(\mathrm{n}=4,5)$ alloys at even higher temperatures $[74,79-81]$.
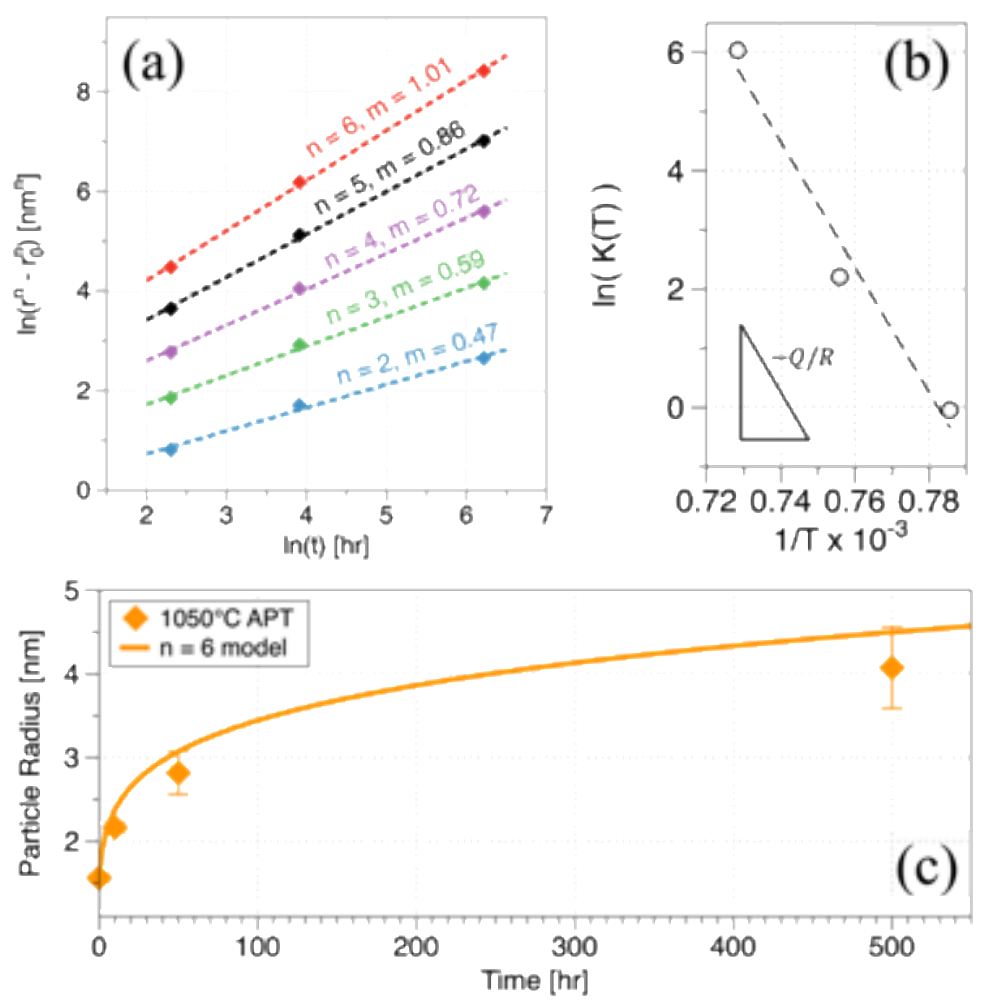

Fig. 11. Error bars shown illustrate the $95 \%$ confidence intervals for measured particle size distributions.

Using the average precipitate radii reported in Table 3 and a power law exponent of $n=6$, the values $R^{6}-R_{0}^{6}$ were plotted as a function of time for particles coarsened at $1000^{\circ} \mathrm{C}(0-1 \mathrm{~h})$, $1050^{\circ} \mathrm{C}(0-500 \mathrm{~h})$, and $1100^{\circ} \mathrm{C}(0-1 \mathrm{~h})$. The natural logarithm of the slopes of the coarsening 
curves, previously defined as $K(T)=k * \exp (-Q / R T)$ in (Eq. 10), result in the temperature dependent linear regression, plotted in Fig. 11(b):

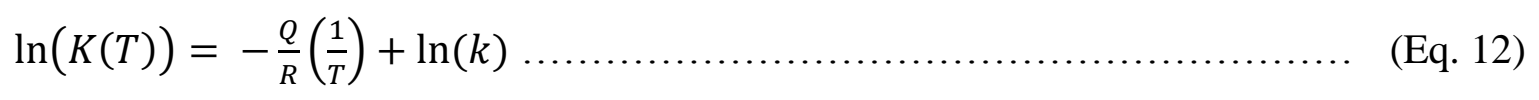

From the linear fit of $\ln (K(T))$ vs. $1 / T$, the corresponding activation energy for coarsening was calculated to be $Q=880 \mathrm{~kJ} / \mathrm{mol}$ with a corresponding pre-exponential constant $k=9.65387455 \times 10^{35} h^{-1}$. This $\mathrm{n}=6$ model fit is overlaid with the experimentally measured APT data for the long-term coarsening behavior of the (Y,Al,O) precipitates for the $1050^{\circ} \mathrm{C}$ condition in Fig. 11(c) with very good agreement between simulated and experimental results. The existence of such sluggish coarsening kinetics with an $n=6$ dependence has been previously noted for ODS alloys fit using identical methodologies [74, 79]. This higher order $n=5,6$ dependence was attributed to coarsening through a pipe dislocation coarsening mechanism, where 3D precipitates coarsen through 1D diffusion of solute along dislocations that intersect the growing precipitates. In the case of this alloy, the high concentration of Al atoms (about 1 in every 10 atoms in the microstructure) and the fast diffusion of oxygen in the Fe lattice would suggest that the diffusion of yttrium through the FeCrAl matrix should be the rate-limiting step for particle coarsening.

However, in the present case particle coarsening is taking place within powders that have undergone significant abnormal grain growth through secondary recrystallization phenomena (Fig. 3). This would mean that the recrystallization front would have swept away the high density of dislocations and other defects along which the rate limiting solute would have traveled. Thus, it is surprising that high high-order reaction kinetics are noted for the current system. This abnormal result cannot be explained through APT artifacts such as trajectory aberrations, since the correction for matrix contributions would only decrease the precipitate sizes and result in even more sluggish coarsening kinetics. In fact, even if no aberration correction was performed on the current system, the corresponding value for $\mathrm{n}$ still is calculated to be between 5 and 6 . In addition, prior derivations of particle coarsening kinetics where dislocation or grain boundary diffusion are supplemented by bulk diffusion through the matrix result in $n=3$ power law dependences [82]. Instead, it may be the case that the previous work on particle coarsening for ODS $\mathrm{FeCr}$ and $\mathrm{FeCrAl}$ alloys may be dominated by a different higher order mechanism for growth since the results in this study on recrystallized powders qualitatively matches coarsening kinetics reported elsewhere without the existence of a high density of dislocation networks within the microstructure. Thus, future work should be performed to provide insights into the underlying fundamental mechanisms for precipitate growth in these alloys. 


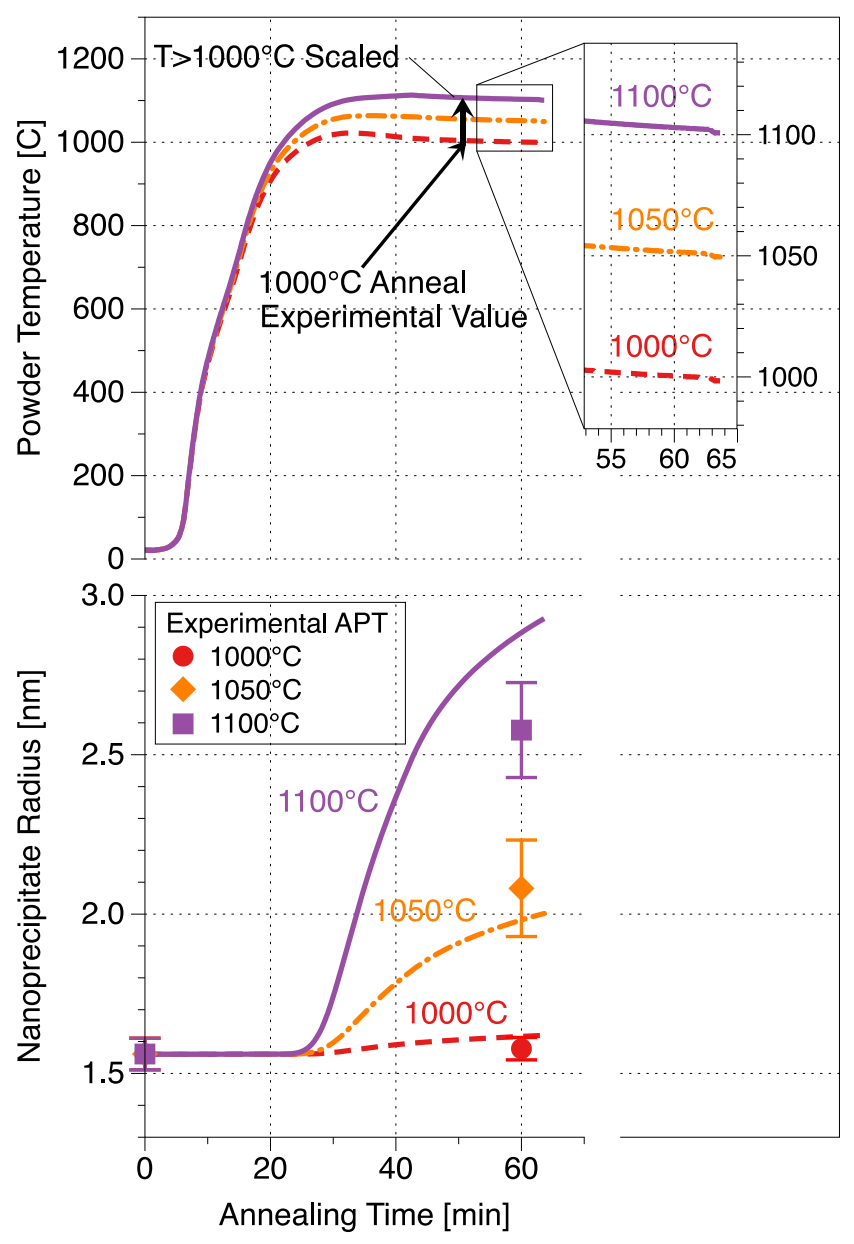

Fig. 12. Simulated time-temperature evolution of $(\mathrm{Y}, \mathrm{Al}, \mathrm{O})$ precipitates for simulated preextrusion annealing treatments at 1000,1050 , and $1100^{\circ} \mathrm{C}$. Error bars for measured APT data indicate $95 \%$ confidence intervals.

Although the long term $(\sim 500 \mathrm{~h})$ coarsening behavior is important for the accurate estimation of coarsening kinetic modeling, the primary focus of this work is on the coarsening behavior of these nanoprecipitate populations during thermomechanical treatments associated with the production of components for nuclear reactors; thus, it follows that one of the major objectives is the application of this coarsening model to the prediction of precipitate sizes for heat treatments expected during ODS FeCrAl consolidation stages such as extrusion. A temperature profile was previously recorded for powder heated to $1000^{\circ} \mathrm{C}$ in an extrusion can in Fig. 2 using an embedded thermocouple at the center of the powder volume. Using this experimentally measured temperature profile, appropriate scaling was performed to simulate the corresponding temperature profiles that would be associated with equivalent $1 \mathrm{~h}$ anneals at either $1050^{\circ} \mathrm{C}$ or $1100^{\circ} \mathrm{C}$. Using the simulated temperature profile, the particle coarsening model was utilized to estimate the time-temperature evolution of the precipitate radii at each annealing temperature. Due to the fast nucleation and growth kinetics noted in both the SANS and APT experimental data, it was assumed that precipitates had already nucleated and grown to equilibrium sizes assumed equivalent to the measured size for the $\mathrm{ZY} 10 \mathrm{C} 15$ sample $\left(\mathrm{R}_{0}=1.56\right.$ 
$\mathrm{nm}$ at $\mathrm{t}=0 \mathrm{~min}$.). Although this results in the simulated existence of nanoprecipitates at room temperature prior to heating the powder, the assumption is valid due to the high activation energy for coarsening that results in negligible precipitate growth until temperatures have well exceeded the temperature at which these precipitates were noted to finish the growth stage $\left(\sim 600^{\circ} \mathrm{C}\right.$ from in-situ SANS results).

Fig. 12 shows both the experimental/simulated temperature profiles and the corresponding simulated coarsening of $(\mathrm{Y}, \mathrm{Al}, \mathrm{O})$ nanoprecipitates at 1000,1050 , and $1100^{\circ} \mathrm{C}$ target annealing temperatures for $1 \mathrm{~h}$ extrusion can heat treatments. Due to the high activation energy measured for coarsening $(\sim 880 \mathrm{~kJ} / \mathrm{mol})$, measurable precipitate growth did not occur until the temperature exceeded $\sim 1000^{\circ} \mathrm{C}$. However, precipitates had almost doubled in size for the $1100^{\circ} \mathrm{C}$ anneal even with the initial sluggish coarsening due to the heating of the powder. The simulated precipitate size slightly overestimated the size in comparison with the measured $1100^{\circ} \mathrm{C}$ value, but this is easily explained due to slightly different experimental parameters for the production of the ZY11C60 (CrAZY_H1) APT specimen. This specific alloy was prepared using a larger extrusion can with double the powder mass as the rest of the specimens, which would result in a slower heating rate for the larger sample mass with an equivalent heat flux. Regardless, the long-term coarsening model fits the short-term coarsening data quite well and can be used practically to estimate particle coarsening in ODS FeCrAl alloys produced for applications requiring a careful control of alloy sink strength.

\subsection{Sink Strength Implications for ODS FeCrAl}

The importance of the aforementioned particle coarsening analysis stems from the design of ODS alloys for nuclear applications requiring high sink strength. In nuclear reactor environments, different types of defects become mobile as the temperature increases and are usually discussed as a function of homologous temperature ( $\left.\mathrm{T} / \mathrm{T}_{\mathrm{M}}\right)$, the ratio of the temperature of interest to the melting temperature of the alloy. It has been previously shown that microstructural features such as pre-existing network dislocations, grain boundaries, and precipitates can act as sites for point-defect recombination in irradiated alloys and can thereby allay microstructural changes that would have otherwise occurred from the interaction of supersaturated point defects within the material [1]. In lower-temperature irradiation conditions $\left(\mathrm{T} / \mathrm{T}_{\mathrm{M}}<0.4\right)$, which would be expected for ODS FeCrAl alloys designed for ATF cladding applications, the mitigation of irradiation-induced hardening phenomena will require a combined sink strength approaching or exceeding $\sim 10^{16} \mathrm{~m}^{-2}$ [83]. In intermediate irradiation temperature regimes characteristic of advanced fission reactors $\left(0.3<\mathrm{T} / \mathrm{T}_{\mathrm{M}}<0.6\right)$ where void swelling becomes a prominent issue, sink strengths greater than $\sim 10^{15} \mathrm{~m}^{-2}$ would be required; however, this required sink strength increases to $\sim 10^{16} \mathrm{~m}^{-2}$ for fusion reactor conditions where helium exacerbates the void swelling phenomenon due to the helium stabilization of cavities [1].

Depending on the application for the ODS alloy, the sink strength requirements can thus vary from $10^{15}-10^{16} \mathrm{~m}^{-2}$ at a minimum for these alloys to be considered irradiation resistant in the targeted irradiation dose/temperature regimes. The overall sink strength will be a function of the grain boundary sink strength, precipitate sink strength, dislocation sink strength within the material. Considering the tabulated results for the current CrAZY ODS FeCrAl alloy powders examined in this work, the grains have been recrystallized to tens of microns in diameter, which results in a negligibly low grain boundary and dislocation sink strength (since the dislocations will have been swept away by the grain boundary recrystallization front). Consequently, for the 
current discussion only the precipitate sink strength $\left(S_{p}=4 \pi R_{p} N_{p}\right)$ will be discussed where $R_{p}$ and $N_{p}$ are the precipitate radius and number density, respectively.

The maximum sink strength in this study corresponds to the CrAZY powder annealed for only 15 minutes at $1000^{\circ} \mathrm{C}(\mathrm{ZY} 10 \mathrm{C} 15)$ and is calculated to be $9.4 \times 10^{15} \mathrm{~m}^{2}$. After annealing at $1000^{\circ} \mathrm{C}$ for $1 \mathrm{~h}$, the sink strength only marginally decreases to $8.3 \times 10^{15} \mathrm{~m}^{2}$. If the temperature of the $1 \mathrm{~h}$ pre-extrusion anneal is increased to $1050^{\circ} \mathrm{C}$ or $1100^{\circ} \mathrm{C}$, the sink strength falls by almost an order of magnitude to $2.9 \times 10^{15} \mathrm{~m}^{2}$ and $2.6 \times 10^{15} \mathrm{~m}^{2}$, respectively. A more homogeneous population of nanoprecipitates is going to allow for the more effective Zener pinning of grain boundaries; furthermore, a more densely populated matrix of precipitates is going to increase the density of dislocations since more precipitates are available for the pinning of gliding dislocations. This suggests that the precipitate sink strength is also going to impact, and in many cases dominate, the other sink strength terms depending on the alloy's processing stages. This also means that simply increasing the extrusion temperature to create more ductile ODS FeCrAl alloys for thin-walled tube fabrication may be at the expense of the very irradiation resistance that these ODS alloys were designed to achieve [49]. This also applies to the design of recrystallized ODS $\mathrm{FeCr}$ and $\mathrm{FeCrAl}$ alloys for $\mathrm{ATF}$ applications [84], since the additional holding of these alloys at $1150^{\circ} \mathrm{C}$ for $1 \mathrm{~h}$ to create a fully recrystallized microstructure may result in enough precipitate coarsening to fall below the limits required to maintain irradiationhardening resistance in LWR operating conditions.

\section{Conclusions}

The nucleation, growth, and coarsening of the fine-scale (Y,Al,O) nanoprecipitates within mechanically alloyed ODS FeCrAl CrAZY alloy powders was studied using both atom probe tomography and small angle neutron scattering techniques. The nucleation and growth of the nanoprecipitates occurs at low temperature $\left(200-600^{\circ} \mathrm{C}\right)$, as indicated by in-situ SANS results. The precipitates then remain stable in size until the temperature rises to a sufficient level to activate the coarsening of the precipitates through Ostwald ripening. The coarsening of the nanoprecipitates aged from $1-500 \mathrm{~h}$ at $1050^{\circ} \mathrm{C}$ follow $\mathrm{n}=6$ power law coarsening kinetics but the existence of the recrystallized powder microstructure suggests that current dislocation-assisted coarsening mechanisms do not satisfactorily explain the high power law exponent. Comparisons of the $\mathrm{Y}$ to $\mathrm{Al}$ concentrations within nanoprecipitates suggest a YAG type composition for newly formed $(\mathrm{Y}, \mathrm{Al}, \mathrm{O})$ nanoprecipitates, while compositions of larger precipitates appear to shift toward the YAP composition for sufficiently large ageing times at high temperature. APT and magnetic SANS results suggest a defective structure for the nanoprecipitates, as measured Aratios deviate significantly from computed ideal A-ratios for expected structures for stochiometric (Y,Al,O) phases. These deviations were explained through a combination of possible matrix contents within the nanoprecipitates and particle coherency within the ODS FeCrAl matrix. Finally, calculations were performed to compare the sink strength of these alloys as a function of observed particle coarsening. The results indicate the need to consider the potentially detrimental effect of high-temperature thermomechanical processes on the irradiation resistance of ODS alloys through thermally activated particle coarsening phenomena. 


\section{Acknowledgements}

This work was funded primarily by the Office of Fusion Energy Sciences. Neutron scattering experiments were performed at the High-Flux Isotope Reactor (HFIR) at Oak Ridge National Laboratory (ORNL) under proposals 18169.1 and 20093.1. This material is based upon work supported under a Department of Energy Nuclear Energy University Programs (NEUP) Graduate Fellowship. The authors acknowledge and thank Gregory Cox and Tom Geer for their efforts in this project. A special thanks is also extended to Kevin Field and Brian Wirth for their insightful discussions on the subject over the course of this project. An acknowledgement is also extended to Lisa Debeer-Schmitt for helping to facilitate the SANS data acquisition.

\section{References}

[1] S.J. Zinkle, L.L. Snead, Designing Radiation Resistance in Materials for Fusion Energy, Annual Review of Materials Research 44(1) (2014) 241-267.

[2] B.A. Pint, K.A. Terrani, M.P. Brady, T. Cheng, J.R. Keiser, High temperature oxidation of fuel cladding candidate materials in steam-hydrogen environments, Journal of Nuclear Materials 440(1-3) (2013) 420-427.

[3] S. Dryepondt, K.A. Unocic, D.T. Hoelzer, C.P. Massey, B.A. Pint, Development of low-Cr ODS FeCrAl alloys for accident-tolerant fuel cladding, Journal of Nuclear Materials 501 (2018) 59-71.

[4] B.A. Pint, S. Dryepondt, K.A. Unocic, D.T. Hoelzer, Development of ODS FeCrAl for Compatibility in Fusion and Fission Energy Applications, JOM 66(12) (2014) 2458-2466. [5] B.A. Pint, K.A. Terrani, Y. Yamamoto, L.L. Snead, Material selection for accident tolerant fuel cladding, Metallurgical and Materials Transactions E 2(3) (2015) 190-196.

[6] G. Korb, M. Rühle, H.-P. Martinz, New Iron-Based ODS-Superalloys for High Demanding Applications, ASME 1991 International Gas Turbine and Aeroengine Congress and Exposition, American Society of Mechanical Engineers, 1991, pp. V005T12A015-V005T12A015.

[7] C. Capdevila Montes, H.K.D.H. Bhadeshia, Influence of Deformation on Recrystallization of an Yttrium Oxide Dispersion-Strengthened Iron Alloy (PM2000), Advanced Engineering Materials 5(4) (2003) 232-237.

[8] T. Chou, Recrystallisation behaviour and grain structure in mechanically alloyed oxide dispersion strengthened MA956 steel, Materials Science and Engineering: A 223(1-2) (1997) 7890.

[9] G. Pimentel, J. Chao, C. Capdevila, Recrystallization Process in Fe-Cr-Al Oxide DispersionStrengthened Alloy: Microstructural Evolution and Recrystallization Mechanism, Jom 66(5) (2014) 780-792.

[10] J. Ejenstam, M. Thuvander, P. Olsson, F. Rave, P. Szakalos, Microstructural stability of Fe$\mathrm{Cr}-\mathrm{Al}$ alloys at $450-550^{\circ} \mathrm{C}$, Journal of Nuclear Materials 457 (2015) 291-297.

[11] S. Kobayashi, T. Takasugi, Mapping of $475^{\circ} \mathrm{C}$ embrittlement in ferritic $\mathrm{Fe}-\mathrm{Cr}-\mathrm{Al}$ alloys, Scripta Materialia 63(11) (2010) 1104-1107.

[12] C. Capdevila, M.K. Miller, K.F. Russell, J. Chao, J.L. González-Carrasco, Phase separation in PM 2000 ${ }^{\mathrm{TM}}$ Fe-base ODS alloy: Experimental study at the atomic level, Materials Science and Engineering: A 490(1-2) (2008) 277-288.

[13] C. Capdevila, M.K. Miller, J. Chao, Phase separation kinetics in a Fe-Cr-Al alloy, Acta Materialia 60(12) (2012) 4673-4684. 
[14] C. Capdevila, M.K. Miller, K.F. Russell, Aluminum partitioning during phase separation in $\mathrm{Fe}-20 \% \mathrm{Cr}-6 \% \mathrm{Al}$ ODS alloy, Journal of Materials Science 43(11) (2008) 3889-3893.

[15] K.G. Field, K.C. Littrell, S.A. Briggs, Precipitation of $\alpha^{\prime}$ in neutron irradiated commercial FeCrAl alloys, Scripta Materialia 142 (2018) 41-45.

[16] M.H. Mathon, Y. de Carlan, G. Geoffroy, X. Averty, A. Alamo, C.H. de Novion, A SANS investigation of the irradiation-enhanced $\alpha-\alpha^{\prime}$ phases separation in 7-12 $\mathrm{Cr}$ martensitic steels, Journal of Nuclear Materials 312(2-3) (2003) 236-248.

[17] F. Soisson, T. Jourdan, Radiation-accelerated precipitation in $\mathrm{Fe}-\mathrm{Cr}$ alloys, Acta Materialia 103 (2016) 870-881.

[18] C. Capdevila, M.K. Miller, I. Toda, J. Chao, Influence of the $\alpha-\alpha^{\prime}$ phase separation on the tensile properties of Fe-base ODS PM 2000 alloy, Materials Science and Engineering: A 527(2930) (2010) 7931-7938.

[19] M. Terada, M.F. Hupalo, I. Costa, A.F. Padilha, Effect of alpha prime due to $475^{\circ} \mathrm{C}$ aging on fracture behavior and corrosion resistance of DIN 1.4575 and MA 956 high performance ferritic stainless steels, Journal of materials science 43(2) (2008) 425-433.

[20] B. Dubiel, W. Osuch, M. Wróbel, P. Ennis, A. Czyrska-Filemonowicz, Correlation of the microstructure and the tensile deformation of incology MA956, Journal of materials processing technology 53(1-2) (1995) 121-130.

[21] C.H. Zhang, A. Kimura, R. Kasada, J. Jang, H. Kishimoto, Y.T. Yang, Characterization of the oxide particles in Al-added high-Cr ODS ferritic steels, Journal of Nuclear Materials 417(13) (2011) 221-224.

[22] K.A. Unocic, B.A. Pint, D.T. Hoelzer, Advanced TEM characterization of oxide nanoparticles in ODS Fe-12Cr-5Al alloys, Journal of materials science 51(20) (2016) 91909206.

[23] P. Dou, A. Kimura, T. Okuda, M. Inoue, S. Ukai, S. Ohnuki, T. Fujisawa, F. Abe, Polymorphic and coherency transition of $\mathrm{Y}-\mathrm{Al}$ complex oxide particles with extrusion temperature in an Al-alloyed high-Cr oxide dispersion strengthened ferritic steel, Acta Materialia 59(3) (2011) 992-1002.

[24] M. Klimiankou, R. Lindau, A. Möslang, J. Schröder, TEM study of PM 2000 steel, Powder Metallurgy 48(3) (2013) 277-287.

[25] L.L. Hsiung, M.J. Fluss, A. Kimura, Structure of oxide nanoparticles in Fe-16Cr MA/ODS ferritic steel, Materials Letters 64(16) (2010) 1782-1785.

[26] L.L. Hsiung, M.J. Fluss, S.J. Tumey, B.W. Choi, Y. Serruys, F. Willaime, A. Kimura, Formation mechanism and the role of nanoparticles in Fe-Cr ODS steels developed for radiation tolerance, Physical Review B 82(18) (2010).

[27] D.T. Hoelzer, K.A. Unocic, M.A. Sokolov, T.S. Byun, Influence of processing on the microstructure and mechanical properties of 14YWT, Journal of Nuclear Materials 471 (2016) 251-265.

[28] C.P. Massey, S.L. Dryepondt, P.D. Edmondson, K.A. Terrani, S.J. Zinkle, Influence of Mechanical Alloying and Extrusion Conditions on the Microstructure and Tensile Properties of Low-Cr ODS FeCrAl Alloys, Journal of Nuclear Materials (In-review).

[29] S.L. Dryepondt, C.P. Massey, M.N. Gussev, Milestone Report: M3FT-17OR020202081, Production and Characterization of Large Batch FeCrAl ODS Alloy, 2017.

[30] M.K. Miller, K.F. Russell, Atom probe specimen preparation with a dual beam SEM/FIB miller, Ultramicroscopy 107(9) (2007) 761-6. 
[31] C.M. Parish, N.K. Kumar, L.L. Snead, P.D. Edmondson, K.G. Field, C. Silva, A.M. Williams, K. Linton, K.J. Leonard, LAMDA: irradiated-materials microscopy at Oak Ridge National Laboratory, Microscopy and Microanalysis 21(S3) (2015) 1003-1004.

[32] D. Vaumousse, A. Cerezo, P. Warren, A procedure for quantification of precipitate microstructures from three-dimensional atom probe data, Ultramicroscopy 95 (2003) 215-221. [33] A. Cerezo, L. Davin, Aspects of the observation of clusters in the 3-dimensional atom probe, Surface and Interface Analysis 39(2-3) (2007) 184-188.

[34] L.T. Stephenson, M.P. Moody, P.V. Liddicoat, S.P. Ringer, New techniques for the analysis of fine-scaled clustering phenomena within atom probe tomography (APT) data, Microscopy and Microanalysis 13(6) (2007) 448-463.

[35] E.A. Marquis, J.M. Hyde, Applications of atom-probe tomography to the characterisation of solute behaviours, Materials Science and Engineering: R: Reports 69(4-5) (2010) 37-62.

[36] M. Bachhav, G. Robert Odette, E.A. Marquis, $\alpha^{\prime}$ precipitation in neutron-irradiated $\mathrm{Fe}-\mathrm{Cr}$ alloys, Scripta Materialia 74 (2014) 48-51.

[37] S.A. Briggs, P.D. Edmondson, K.C. Littrell, Y. Yamamoto, R.H. Howard, C.R. Daily, K.A. Terrani, K. Sridharan, K.G. Field, A combined APT and SANS investigation of $\alpha$ ' phase precipitation in neutron-irradiated model FeCrAl alloys, Acta Materialia 129 (2017) 217-228.

[38] P.D. Edmondson, C.M. Parish, R.K. Nanstad, Using complimentary microscopy methods to examine Ni-Mn-Si-precipitates in highly-irradiated reactor pressure vessel steels, Acta Materialia 134 (2017) 31-39.

[39] K. Dawson, S.J. Haigh, G.J. Tatlock, A.R. Jones, Nano-particle precipitation in mechanically alloyed and annealed precursor powders of legacy PM2000 ODS alloy, Journal of Nuclear Materials 464 (2015) 200-209.

[40] B. Gault, M.P. Moody, J.M. Cairney, S.P. Ringer, Atom probe microscopy, Springer, 2012. [41] D.J. Larson, T. Prosa, R.M. Ulfig, B.P. Geiser, T.F. Kelly, Local electrode atom probe tomography, New York, US: Springer Science (2013).

[42] P.D. Edmondson, S.A. Briggs, Y.Yamamoto, R.H. Howard, K. Sridharan, K.A. Terrani, K.G. Field, Irradiation-enhanced $\alpha^{\prime}$ precipitation in model FeCrAl alloys, Scripta Materialia 116 (2016) 112-116.

[43] G.D. Wignall, K.C. Littrell, W.T. Heller, Y.B. Melnichenko, K.M. Bailey, G.W. Lynn, D.A. Myles, V.S. Urban, M.V. Buchanan, D.L. Selby, P.D. Butler, The $40 \mathrm{~m}$ general purpose smallangle neutron scattering instrument at Oak Ridge National Laboratory, Journal of Applied Crystallography 45(5) (2012) 990-998.

[44] K. Dawson, A. Rao, G.J. Tatlock, A.R. Jones, Recovery and recrystallisation in mechanically alloyed and annealed, legacy, FeCrAlY ODS alloy precursor powders, IOP Conference Series: Materials Science and Engineering 89 (2015).

[45] N. Sallez, Recrystallization, abnormal grain growth and ultrafine microstructure of ODS ferritic steels, Grenoble, 2014.

[46] S. Ukai, M. Harada, H. Okada, M. Inoue, S. Nomura, S. Shikakura, K. Asabe, T. Nishida, M. Fujiwara, Alloying design of oxide dispersion strengthened ferritic steel for long life FBRs core materials, Journal of Nuclear Materials 204 (1993) 65-73.

[47] A. Czyrska-Filemonowicz, B. Dubiel, Mechanically alloyed, ferritic oxide dispersion strengthened alloys: structure and properties, Journal of Materials Processing Technology 64(1-

3) (1997) 53-64.

[48] G. Pimentel, C. Capdevila, M.J. Bartolomé, J. Chao, M. Serrano, A. García-Junceda, M. Campos, J.M. Torralba, J. Aldazábal, Advanced FeCrAl ODS steels for high-temperature 
structural applications in energy generation systems, Revista de Metalurgia 48(4) (2012) 303316.

[49] S. Dryepondt, K.A. Unocic, D.T. Hoelzer, C.P. Massey, B.A. Pint, Development of low-Cr ODS FeCrAl alloys for accident-tolerant fuel cladding, Journal of Nuclear Materials (2018).

[50] D. Blavette, F. Vurpillot, P. Pareige, A. Menand, A model accounting for spatial overlaps in 3D atom-probe microscopy, Ultramicroscopy 89(1-3) (2001) 145-153.

[51] C. Hatzoglou, B. Radiguet, P. Pareige, Experimental artefacts occurring during atom probe tomography analysis of oxide nanoparticles in metallic matrix: Quantification and correction, Journal of Nuclear Materials 492 (2017) 279-291.

[52] J.M. Hyde, M.G. Burke, G.D.W. Smith, P. Styman, H. Swan, K. Wilford, Uncertainties and assumptions associated with APT and SANS characterisation of irradiation damage in RPV steels, Journal of Nuclear Materials 449(1-3) (2014) 308-314.

[53] T. Philippe, D. Blavette, Nucleation pathway in coherent precipitation, Philosophical Magazine 91(36) (2011) 4606-4622.

[54] G. Kostorz, Small-angle scattering and its applications to materials science, Treatise on Materials Science \& Technology 1979, pp. 227-289.

[55] B.T.M. Willis, C.J. Carlile, Experimental Neutron Scattering, OUP Oxford2017.

[56] V.K. Peterson, G.J. Kearley, Neutron Applications in Materials for Energy: An Overview, Neutron Applications in Materials for Energy2015, pp. 1-9.

[57] A.J. Jackson, Introduction to small-angle neutron scattering and neutron reflectometry, NIST Center for Neutron Research (2008) 1-24.

[58] J.S. Pedersen, Small-angle scattering from precipitates: analysis by use of a polydisperse hard-sphere model, Physical Review B 47(2) (1993) 657.

[59] M.J. Alinger, G.R. Odette, D.T. Hoelzer, The development and stability of Y-Ti-O nanoclusters in mechanically alloyed $\mathrm{Fe}-\mathrm{Cr}$ based ferritic alloys, Journal of Nuclear Materials 329-333 (2004) 382-386.

[60] O. Glatter, A new method for the evaluation of small-angle scattering data, Journal of Applied Crystallography 10(5) (1977) 415-421.

[61] J.S. Pedersen, Determination of size distribution from small-angle scattering data for systems with effective hard-sphere interactions, Journal of applied crystallography 27(4) (1994) 595-608.

[62] R. Coppola, M. Klimenkov, R. Lindau, A. Möslang, M. Valli, A. Wiedenmann, Recent applications of small-angle neutron scattering in the characterization of irradiated steels for nuclear technologies, Journal of Nuclear Materials 409(2) (2011) 100-105.

[63] J. Shamblin, C.L. Tracy, R.C. Ewing, F. Zhang, W. Li, C. Trautmann, M. Lang, Structural response of titanate pyrochlores to swift heavy ion irradiation, Acta Materialia 117 (2016) 207-

215.

[64] W. Blau, S. Mager, E. Wieser, Determination of Localized Magnetic Moments in Fe-Cr-Al Alloys and the Electron Structure, physica status solidi (b) 81(2) (1977) 535-544.

[65] D. Brown, P. Kienzle, Neutron activation and scattering calculator, NIST Center for Neutron Research. (accessed 7.2018).

[66] P. Dou, A. Kimura, T. Okuda, M. Inoue, S. Ukai, S. Ohnuki, T. Fujisawa, F. Abe, Effects of extrusion temperature on the nano-mesoscopic structure and mechanical properties of an Alalloyed high-Cr ODS ferritic steel, Journal of Nuclear Materials 417(1-3) (2011) 166-170. [67] L. Ratke, P. Voorhees, Growth and Coarsening: Ripening in Materials Processing. 2002, Berlin: Springer Verlag. 
[68] A.J. Ardell, Temporal behavior of the number density of particles during Ostwald ripening, Materials Science and Engineering: A 238(1) (1997) 108-120.

[69] A.J. Ardell, Microstructural stability at elevated temperatures, Journal of the European Ceramic Society 19(13-14) (1999) 2217-2231.

[70] A. Baldan, Review Progress in Ostwald ripening theories and their applications to nickelbase superalloys Part I: Ostwald ripening theories, Journal of Materials Science 37(11) (2002) 2171-2202.

[71] C. Jayanth, P. Nash, Factors affecting particle-coarsening kinetics and size distribution, Journal of materials science 24(9) (1989) 3041-3052.

[72] I.M. Lifshitz, V.V. Slyozov, The kinetics of precipitation from supersaturated solid solutions, Journal of physics and chemistry of solids 19(1-2) (1961) 35-50.

[73] C. Wagner, Theorie der alterung von niederschlägen durch umlösen (Ostwald-reifung), Zeitschrift für Elektrochemie, Berichte der Bunsengesellschaft für physikalische Chemie 65(7-8) (1961) 581-591.

[74] M.J. Alinger, On the formation and stability of nanometer scale precipitates in ferritic alloys during processing and high temperature service, Materials, University of California, Santa Barbara, 2004.

[75] L. Ratke, D. Uffelmann, W. Bender, P. Voorhees, Theory of Ostwald ripening due to a second-order reaction, Scripta metallurgica et materialia 33(3) (1995) 363-367.

[76] M. Speight, Growth kinetics of grain-boundary precipitates, Acta Metallurgica 16(1) (1968) 133-135.

[77] A. Ardell, On the coarsening of grain boundary precipitates, Acta Metallurgica 20(4) (1972) 601-609.

[78] R. Vengrenovich, Y.V. Gudyma, S. Yarema, Ostwald ripening under dislocation diffusion, Scripta Materialia 46(5) (2002) 363-367.

[79] N.J. Cunningham, M.J. Alinger, D. Klingensmith, Y. Wu, G.R. Odette, On nano-oxide coarsening kinetics in the nanostructured ferritic alloy MA957: A mechanism based predictive model, Materials Science and Engineering: A 655 (2016) 355-362.

[80] Y. Ijiri, N. Oono, S. Ukai, S. Ohtsuka, T. Kaito, Y. Matsukawa, Oxide particle-dislocation interaction in 9Cr-ODS steel, Nuclear Materials and Energy 9 (2016) 378-382.

[81] N.H. Oono, S. Ukai, S. Hayashi, S. Ohtsuka, T. Kaito, A. Kimura, T. Torimaru, K.

Sakamoto, Growth of oxide particles in $\mathrm{FeCrAl}$ - oxide dispersion strengthened steels at high temperature, Journal of Nuclear Materials 493 (2017) 180-188.

[82] J. Hoyt, On the coarsening of precipitates located on grain boundaries and dislocations, Acta metallurgica et materialia 39(9) (1991) 2091-2098.

[83] S.J. Zinkle, J.L. Boutard, D.T. Hoelzer, A. Kimura, R. Lindau, G.R. Odette, M. Rieth, L. Tan, H. Tanigawa, Development of next generation tempered and ODS reduced activation ferritic/martensitic steels for fusion energy applications, Nuclear Fusion 57(9) (2017).

[84] Y. Yano, T. Tanno, H. Oka, S. Ohtsuka, T. Inoue, S. Kato, T. Furukawa, T. Uwaba, T. Kaito, S. Ukai, N. Oono, A. Kimura, S. Hayashi, T. Torimaru, Ultra-high temperature tensile properties of ODS steel claddings under severe accident conditions, Journal of Nuclear Materials 487 (2017) 229-237. 